This is the accepted, peer-reviewed version of the following article:

N. H. Evans and P. D. Beer, Progress in the synthesis and exploitation of catenanes since the Millennium, Chem. Soc. Rev., 2014, 43, 4658-4683.

Which has been published in final form at:

http://pubs.rsc.org/en/content/articlepdf/2014/cs/c4cs00029c 


\title{
Progress in the Synthesis and Exploitation of Catenanes since the Millennium $\dagger$
}

\author{
Nicholas H. Evans*, ${ }^{*}$ and Paul D. Beer*, \\ Received (in $X X X, X X X)$ Xth $X X X X X X X X X 20 X X$, Accepted $X$ th $X X X X X X X X X 20 X X$ \\ ${ }_{5}$ DOI: 10.1039/b000000x
}

Catenanes - molecules consisting of interlocked macrocyclic rings - have been prepared by templation strategies for some thirty years. The utilization of $\mathrm{Cu}^{\mathrm{I}}$ cation, aromatic donor-acceptor interactions and hydrogen bonding assisted self-assembly strategies has led to the construction of numerous examples of these aesthetically pleasing species. This review seeks to discuss key developments in the synthesis and

10 functional application of catenanes that have occurred since the Millennium. The much expanded range of metal cation templates; the genesis and growth of anion templation, as well as the use of alternative supramolecular interactions (halogen bonding and radical templation) and thermodynamically controlled reactions to synthesize catenanes are detailed. The class of catenanes that may be described as "molecular machines” are then highlighted and to conclude, attempts to fabricate catenanes onto surfaces and into

15 metal organic frameworks (MOFs) are discussed.

\section{Introduction}

The preparation and utilization of molecules consisting of interlocked, but not covalently linked, components is an area of intense research activity. Of the considerable collection of 20 interlocked molecules that have been prepared to date, catenanes - molecules consisting of two or more rings that are interlocked are particularly pleasing to the eye. Catenanes and rotaxanes (molecules consisting of stoppered axle(s) components threaded through a ring or rings) constitute the two major classes of 25 interlocked molecular species (Figure 1). (a)

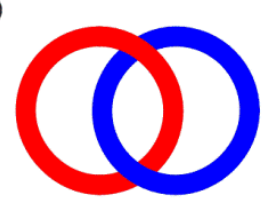

(b)

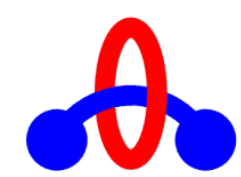

Fig. 1 Schematic representation of simple (a) catenane and (b) rotaxane structures.

Interlocked molecules exhibiting alternative topologies have 30 also been prepared. ${ }^{1}$ These include trefoil ${ }^{2-6}$ and pentafoil ${ }^{7,8}$ knots, with another much celebrated example being Borromean Rings. ${ }^{9}, 10$ Of particular note are the related Solomon Links, which are catenanes consisting of two doubly interlocked rings. ${ }^{11-}$

${ }^{13}$ A number of interlocked cages have also been reported. ${ }^{14-17}$

35 However, examples of such topologically exotic species remain rare.

In contrast, much attention has been granted to the investigation of catenanes (and rotaxanes) due to their perceived potential as useful molecular devices. Their most celebrated 40 application is as "molecular machines" relying on the controlled molecular motion of their interlocked components. ${ }^{18}$ However, opportunities arising from the unique topological scaffolds generated by the mechanical bond(s) of these species have also begun to be exploited. ${ }^{19}$

45 It is well-established that catenanes exist in nature, most notably as interlocked duplex DNA rings. ${ }^{20,} 21$ However, historically the synthesis of these species in the laboratory proved exceedingly challenging. ${ }^{22-24}$ Without doubt, research into catenanes - and interlocked molecules in general - was ignited by 50 Jean-Pierre Sauvage's seminal report in 1983 describing the use of a copper (I) cation as a template to arrange two bidentate ligands in a tetrahedral array as a prelude to cyclization and catenane formation (Figure 2) ${ }^{25}$ Over the following fifteen to twenty years, synthetic strategies harnessing $\mathrm{Cu}^{\mathrm{I}}$ cation $^{26}$, 55 aromatic donor-acceptor interactions ${ }^{27,28}$ and hydrogen bonding ${ }^{29}$ templating interactions were developed, resulting in the construction of numerous catenane species. In this review, we seek to analyse the key recent advances in the chemistry of catenanes. We first provide a brief commentary on the 60 aforementioned template methods used to construct catenanes, before considering the fundamental advances in the templated synthesis of catenanes, namely: (a) the expansion of metal cationic templation beyond copper (I); $(b)$ the utilization of anionic templates; (c) the application of alternative 65 supramolecular interactions (halogen bonding and radical templation) and $(d)$ the use of thermodynamically controlled reactions (including dynamic combinatorial libraries). Following a survey of catenanes that may be considered as "molecular machines", we conclude with an examination of attempts to 70 integrate catenanes onto surfaces and into metal organic frameworks (MOFs). This review is not comprehensive and does not have the intention of cataloguing every literature report of catenanes since the Millennium. We have chosen to exclude 
discussion of polycatenanes that have been recently reviewed comprehensively elsewhere, ${ }^{30}$ as well as catenanes derived from nucleic acids. ${ }^{31-34}$

\section{The templated synthesis of catenanes by copper (I) cations, aromatic acceptor-donor interactions and hydrogen bonds - a brief history and recent developments}

\subsection{Catenane synthesis templated by copper (I) cations}

A copper (I) cation, with a closed shell $\mathrm{d}^{10}$ electronic 10 configuration, has a strong tetrahedral coordination geometry preference. Sauvage exploited this in the preparation of catenanes by employing two bidentate phenanthroline ligands, to coordinate to a single $\mathrm{Cu}^{\mathrm{I}}$ cation. ${ }^{25}$ The production of a [2]catenane was achieved by two strategies as illustrated in Figure 2. The first ${ }_{15}$ clipping - was to form a complex between a $\mathrm{Cu}^{\mathrm{I}}$ cation coordinated to a phenanthroline containing macrocycle and a phenanthroline "thread" appended with phenol groups, which was "clipped" shut by Williamson ether synthesis to form a second, interlocked, ring. By this method, [2]catenane $\neq$ synthesis was
20 accomplished in a yield of $42 \%$. The second route - double clipping - involved coordinating the $\mathrm{Cu}^{\mathrm{I}}$ cation with two identical phenol functionalized phen "threads" which were cyclized simultaneously to yield the same [2]catenane in a 31\% yield. Removal of the $\mathrm{Cu}^{\mathrm{I}}$ cation from this catenane was achieved 25 readily by treatment with $\mathrm{KCN}$, even though it has been demonstrated recently that it is possible to use the less hazardous $\mathrm{NH}_{4} \mathrm{OH}$ to accomplish this transformation. ${ }^{35}$ Crystal structures of both the metallated and metal-free catenane were obtained, which revealed that upon template removal, the two rings are able to 30 glide over one another. ${ }^{36}$

Following on from this first catenane, Sauvage and his coworkers were able to prepare more elaborate examples of catenanes by use of this copper (I) template strategy, such as [3] catenanes $^{37,38}$ and topologically chiral [2]catenanes ${ }^{39}$. A more 35 recent notable development has been the use of Grubbs' catalyst to achieve ring-closing metathesis (RCM) of terminal allyl appended phenanthroline ligands. Impressive yields of cyclization of 88-92\% have been reported for both "clipping” and “double clipping” routes (Figure 3). ${ }^{40,41}$

40

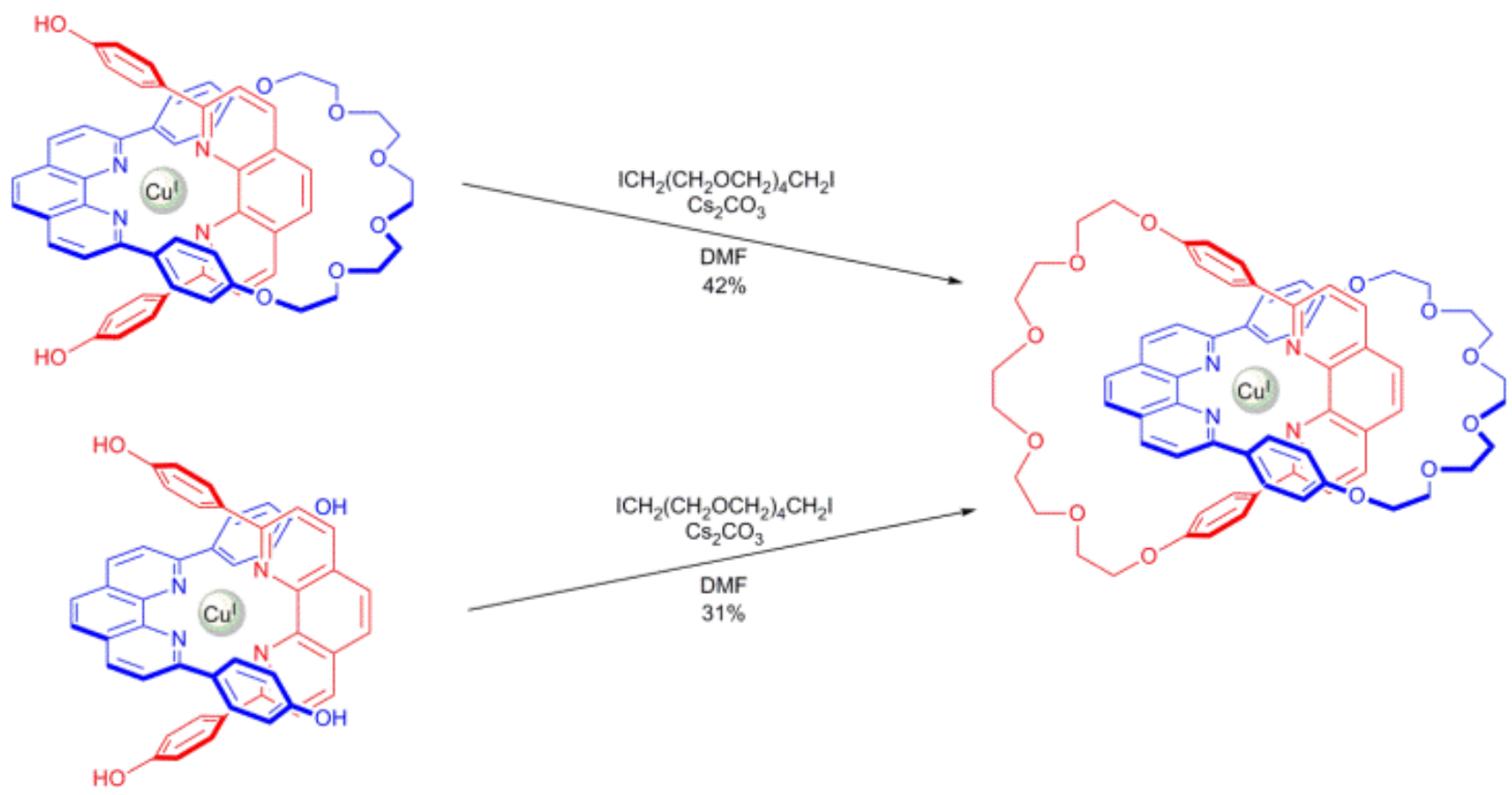

Fig. 2 Sauvage's seminal preparation of a $\mathrm{Cu}^{\mathrm{I}}$ cation template [2]catenane. 


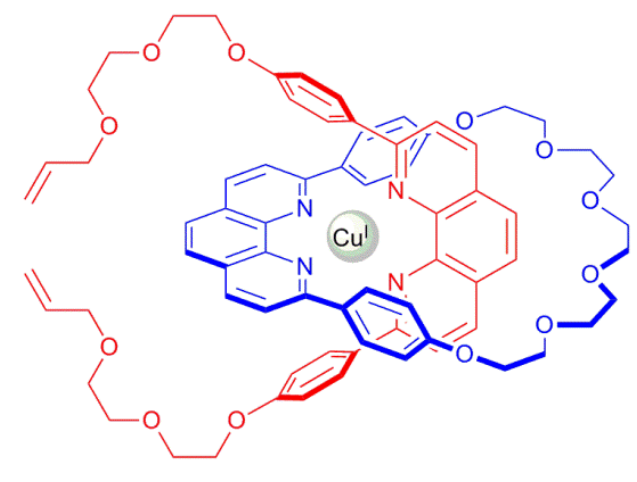

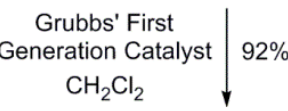

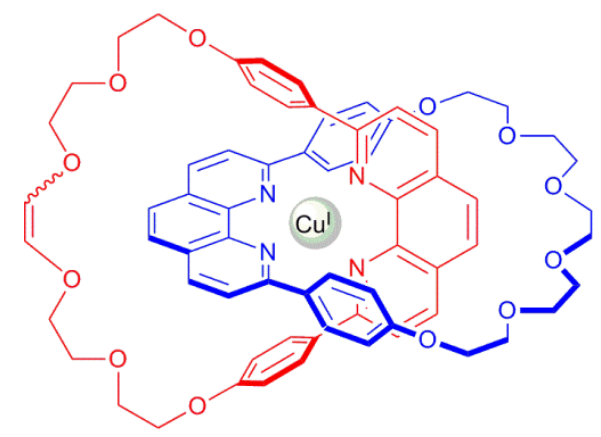

Fig. 3 Example of Sauvage and Grubbs’ high yielding ring closing metathesis synthesis of [2]catenanes.

2.2 Catenane synthesis templated by aromatic donor-acceptor 5 interactions

Catenane synthesis employing aromatic donor-acceptor interactions was pioneered, and has subsequently been thoroughly exploited, by Fraser Stoddart and co-workers. Their first [2]catenane was prepared by clipping a bis-pyridine-bis10 pyridinium molecule with 1,4-bis(bromomethyl)benzene, threaded through bis-para-phenylene-34-crown-10, isolating the catenane in $70 \%$ yield (Figure 4 ). ${ }^{42}$ The crystal structure of the catenane showed face-to-face aromatic donor-acceptor interactions between electron-rich hydroquinone and the electron${ }_{15}$ poor bipyridinium units, while ${ }^{1} \mathrm{H}$ NMR spectroscopy revealed two principal dynamic processes in solution: rotation of the crown ether through the tetracationic cavity, which is much slower than its pirouetting around the tetracationic macrocycle, due to disruption of all aromatic donor-acceptor interactions in 20 the former case, rather than one aromatic donor-acceptor interaction in the latter.

Despite the incompatibility of the tetracationic cyclophane cyclobis(paraquat-para-phenylene) $\mathrm{CBPQT}^{4+}$, the so-called "blue box”, to many reducing agents, nucleophiles and bases, ${ }^{43}$ it is one 25 of the most common macrocyclic components observed in mechanically interlocked structures. Its sustained popularity has been partly fuelled by the development of new reactions that overcome shortcomings of earlier catenane (and rotaxane) syntheses - as identified by Stoddart ${ }^{44}$ - where modest yields, 30 long reaction times (days to even weeks) and operationally challenging conditions (e.g. high pressures) were far from ideal. Stoddart's group have demonstrated the use of amenable ring closing reaction conditions such as CuAAC azide-alkyne cycloadditions and Eglinton alkyne-alkyne couplings, which can 35 be used to prepare catenanes in reasonable and excellent yields respectively (Figure 5). ${ }^{43}$
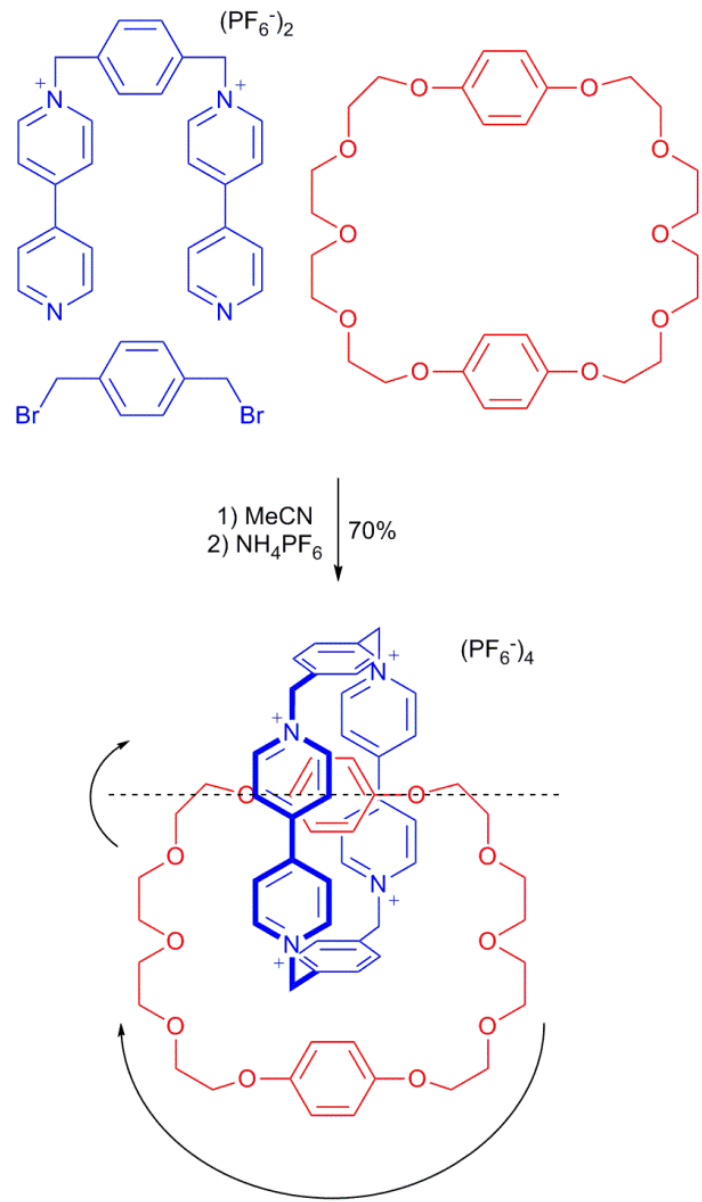

Fig. 4 Stoddart's first [2]catenane synthesis employing charge transfer aromatic donor-acceptor interactions. The principal rotary motion events, 40 as observed by ${ }^{1} \mathrm{H}$ NMR spectroscopy, are marked on the structure of the catenane.
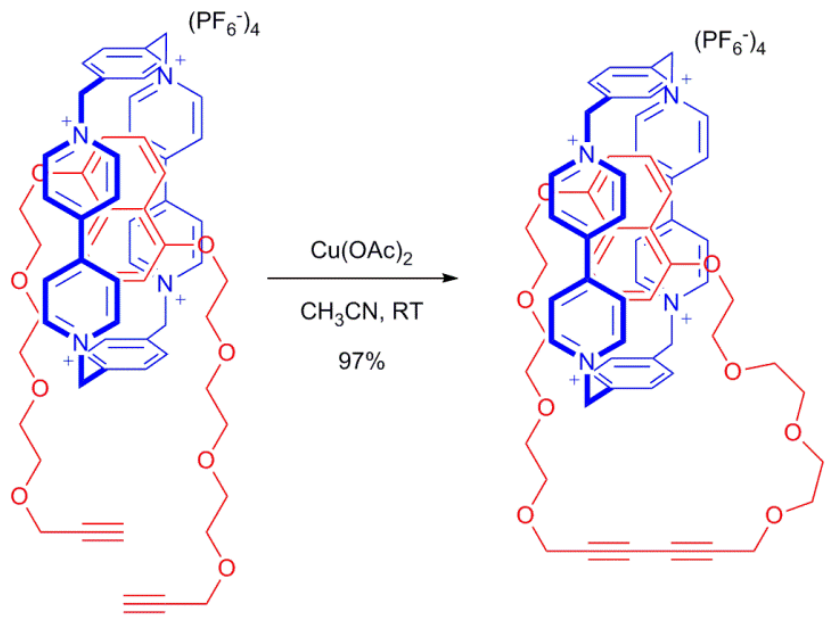

Fig. 5 Charged aromatic donor-acceptor catenane synthesis employing Eglinton alkyne coupling for ring closure. 
It is also important to note that catenanes may also be prepared by using neutral, rather than charged, aromatic donor-acceptor interactions. The first report of such a catenane was made by Sanders and co-workers, who employed Glasser coupling of 5 acetylene terminated electron-poor diimide units (threaded through electron-rich naphthalene crown ethers), to achieve ring closure, and hence catenane synthesis (Figure 6). ${ }^{28}$<smiles>C#CCn1c(=O)c2cc3c(=O)n(CC#C)c(=O)c3cc2c1=O</smiles><smiles>C1=C\OCCOc2cccc3c(cccc23)OCCOCCOCCOCCOc2cccc3c(cccc23)OCCOC/1</smiles>





Fig. 6 Synthesis of a neutral aromatic donor-acceptor [2]catenane.

\section{2.3 Catenane synthesis templated by hydrogen bonds}

Whilst attempting to prepare a macrocycle by cyclizing a bisamine with isophthaloyl dichloride, Hunter isolated a [2]catenane in $34 \%$ yield (Figure 7). ${ }^{45}$ At the same time, Vögtle independently isolated a similar catenane by a slightly different ${ }_{15}$ route. $^{46}$ The principal templating interaction leading to interlocked molecule formation was hydrogen bonding of the amide $\mathrm{N}-\mathrm{H}$ to the carbonyl oxygen.

Leigh and co-workers also serendipitiously prepared hydrogen-bonded [2]catenanes while attempting to synthesise 20 macrocycles. $^{47,}{ }^{48}$ A [2] catenane was isolated in $20 \%$ yield by reacting equimolar quantities of isophthaloyl dichloride and paraxylenediamine (Figure 8). The versatility of the synthetic method was demonstrated by the facile variation of both the bis-acid chloride and aromatic spacer of the bis-amine.

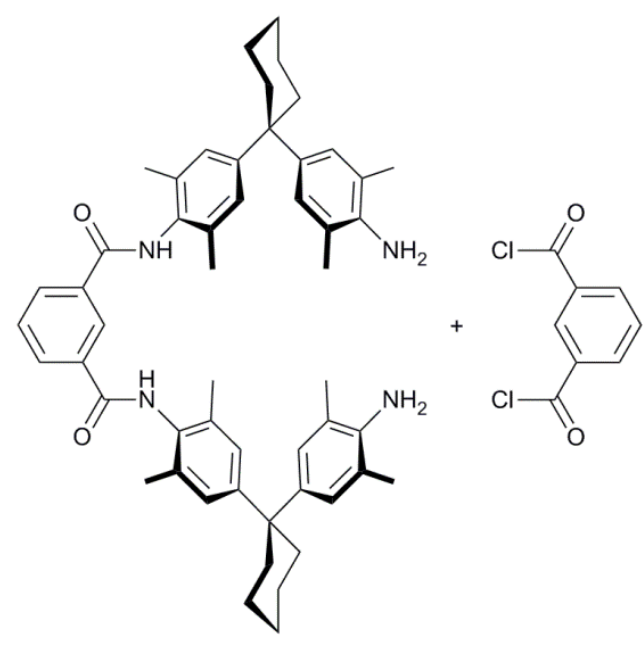

\begin{tabular}{l|l}
$\underset{\mathrm{NEt}_{3}}{\mathrm{CH}_{2} \mathrm{Cl}_{2}}$ & $34 \%$
\end{tabular}

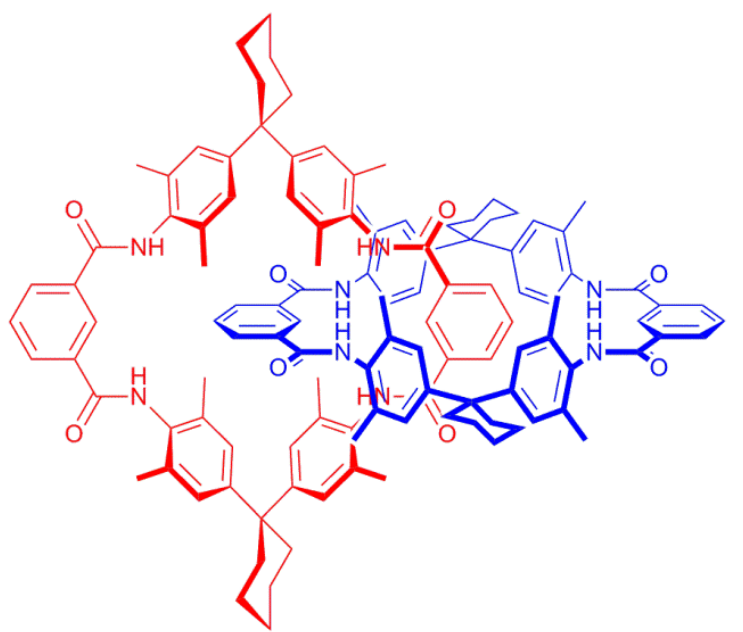

Fig. 7 Hunter's serendipitously discovered hydrogen-bonded [2]catenane.
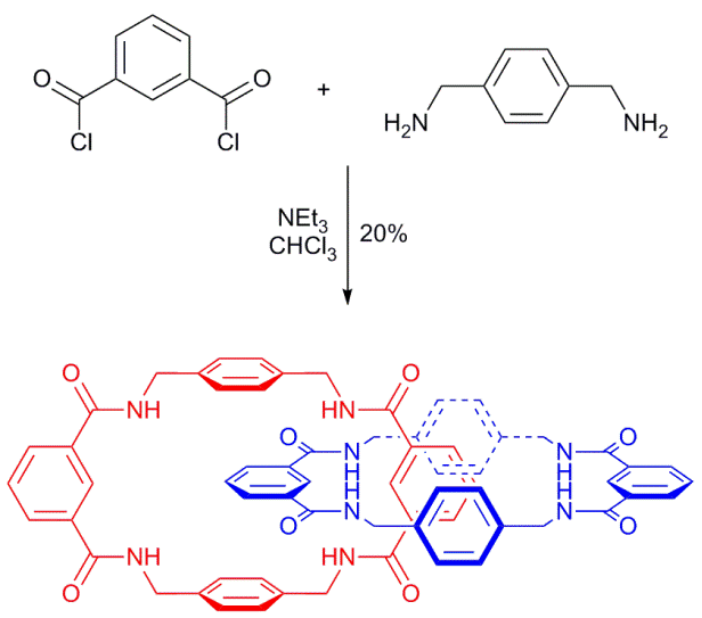

Fig. 8 Leigh's serendipitously discovered hydrogen-bonded [2]catenane. 


\section{Fundamental advances in the synthesis of catenanes}

\subsection{Metal cation templation}

3.1.1 Expanding the range of metal cation templating 5 geometries by substitution of the copper (I) cation

Replacing the $\mathrm{Cu}^{\mathrm{I}}$ cation with other transition metal cations enables the coordination geometry preference of the metal cation template to be changed and exploited for catenane synthesis. This was first demonstrated in 1991, when a [2]catenane was 10 constructed by taking tridentate terpyridine ligands, and employing the octahedral coordination preference of the $\mathrm{Ru}^{\mathrm{II}}$ cation. $^{49}$

Since 2000, many classical transition metal coordination geometries have now been used in the construction of 15 [2]catenanes. It is notable that in many of these investigations Grubbs' catalyzed RCM, as first demonstrated by Sauvage (see above) has been the reaction of choice to achieve macrocyclization. This is exemplified by Leigh and co-workers' synthesis of [2]catenanes utilizing the octahedral preferences of a 20 wide range of $\mathrm{M}^{\mathrm{II}}$ transition metal cations with tridentate bisimino pyridyl ligands functionalized with terminal vinyl groups (Figure 9a). ${ }^{50}$ An analogous catenane was also prepared using the Co ${ }^{\text {III }}$ cation, with bis-anionic pyridine 2, 6-dicarboxamido ligands (Figure $9 b) .{ }^{51}$ In this example, catenane formation required one 25 of the ligands to be macrocyclic; cyclization of two equivalents of bis-vinylic acyclic ligand template to $\mathrm{Co}^{\mathrm{III}}$, led to a noninterlocked figure-of-eight product.

(a)
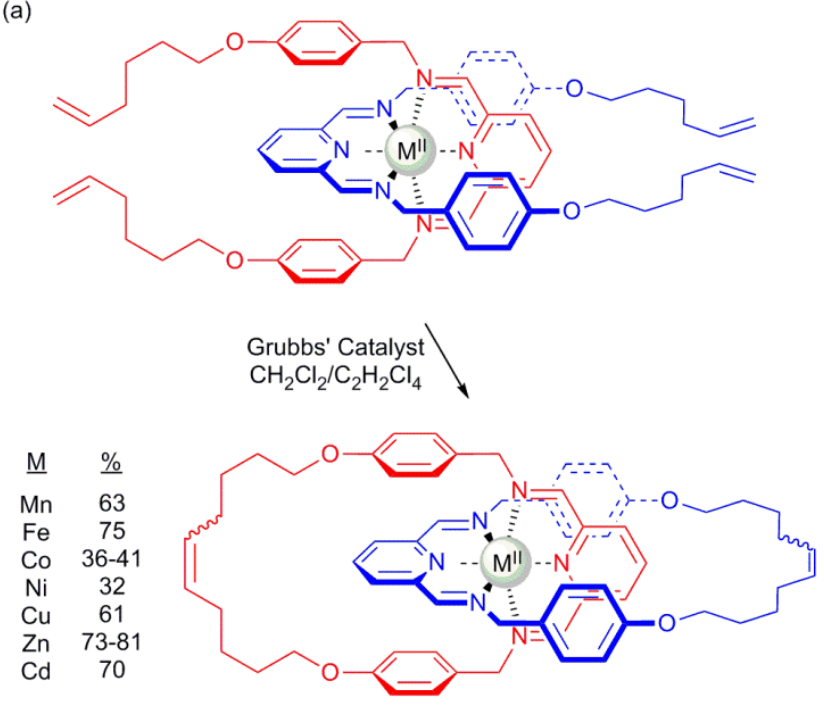

(b)

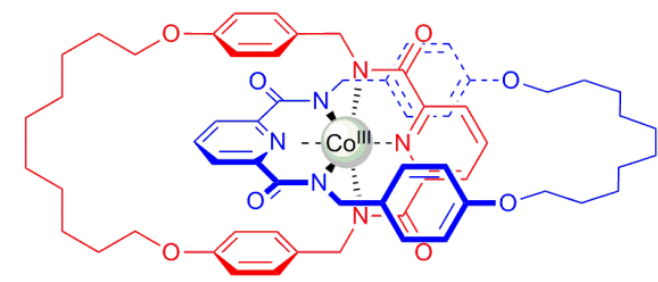

Fig. 9 Catenanes prepared by Leigh et al using octahedral templates: (a) 30 $\mathrm{M}^{\mathrm{II}}$ cations with bis-imino pyridyl ligands, (b) $\mathrm{Co}^{\mathrm{III}}$ cation with pyridine 2, 6-dicarboxamido ligands
Very recently, Sauvage has reported using octahedrally directing $\mathrm{Fe}^{\mathrm{II}}$ or $\mathrm{Co}^{\mathrm{III}}$ cations to template catenane construction, consisting of meridional coordinated 35 diphenylisoquinolinylpyridine ligands (Figure 10). Importantly, it was found that analogous diphenyl terpyridyl ligands were unable to form the necessary 2:1 ligand to metal complex due to steric congestion. $^{52}$

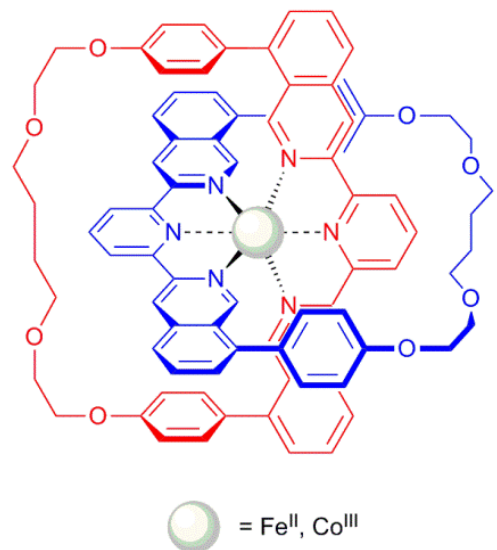

40 Fig. 10 Sauvage's octahedrally template catenane using $\mathrm{Fe}^{\mathrm{II}}$ or $\mathrm{Co}^{\mathrm{III}}$ with diphenylisoquinolinylpyridine ligands.

Leigh's group has prepared a catenane using the $\mathrm{Pd}^{\mathrm{II}}$ cation acting as a square planar stererochemically directing template (Figure 11). ${ }^{53}$ As for the $\mathrm{Co}^{\mathrm{III}}$ pyridine 2,6-dicarboxamide 45 catenane already described, to achieve catenane formation necessitated one of the two ligands (either the tridentate pyridine 2, 6-dicarboxamide, or preferably the monodentate pyridine) to be a pre-formed macrocyclic ring.

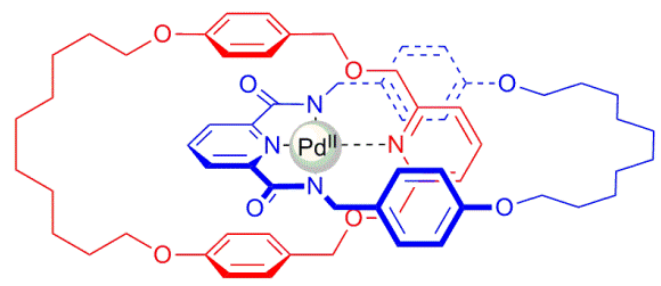

Fig. 11 Leigh's square planar templated [2]catenane.

Use of less common metal geometries has also been reported. For example, a $\mathrm{Zn}^{\text {II }}$ cation has been demonstrated to act as a trigonal bipyramidal stereochemical template, in combination with phenanthroline and terpyridyl ligands (Figure 12a). ${ }^{54}$ The ${ }_{55}$ linear geometry preference of $\mathrm{Au}^{\mathrm{I}}$ arising from its $\mathrm{d}^{10}$ electronic configuration, was employed to synthesize a [2]catenane, in conjunction with two equivalents of a monodentate 2,6dialkylpyridine ligand (Figure 12b). ${ }^{55}$

A rare example of exploiting a main group metal cation, 60 sodium, has been reported recently by Chiu (Figure 13). ${ }^{56}$ An orthogonal assembly was produced by the coordination of 2 eq. of a tri-glycol bis-amine around 1 eq. of $\mathrm{Na}^{+}$cation, which upon double ring Schiff base cyclisation with 2 eq. of isophthaldehyde afforded the catenane. The authors specifically used a non65 coordinating anion salt to maximize the stability of the orthogonal array. The metal free catenane was "trapped" by reduction of the imines using $\mathrm{PhSeH}$ in an isolated yield of $17 \%$. Conformation of the interlocked nature of the catenane was 
provided by solid state crystal structure determination.

(a)



(b)

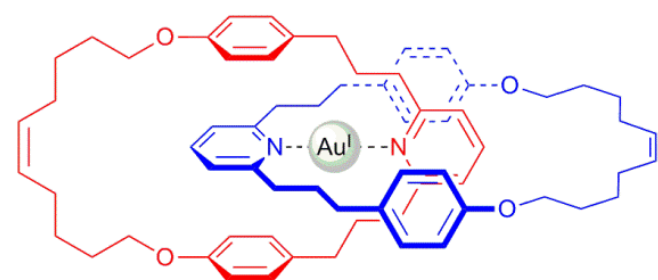

Fig. 12 Examples of [2]catenanes templated using less common (a) trigonal bipyramidal and (b) linear metal cation coordination geometries.

5
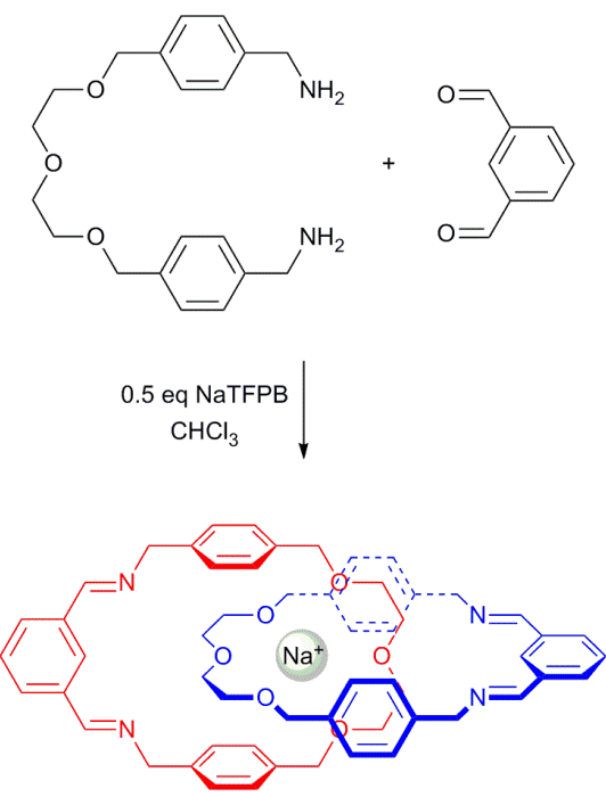

Fig. 13 Synthesis of a $\mathrm{Na}^{+}$templated [2]catenane.

\subsubsection{From passive to active metal templation}

In the examples discussed so far, the metal cation acts solely as a 10 template and plays no role in the actual chemical reaction that achieves cyclization, i.e. it is a "passive" template. A recently developed research theme is the construction of interlocked structures by so-called "active" templation. Here the metal cation can act simultaneously as a template and a reagent (or catalyst) 15 for the reaction that forms the chemical bond that - in the case of a catenane - achieves cyclization affording the interlocked species (Figure 14). ${ }^{57}$

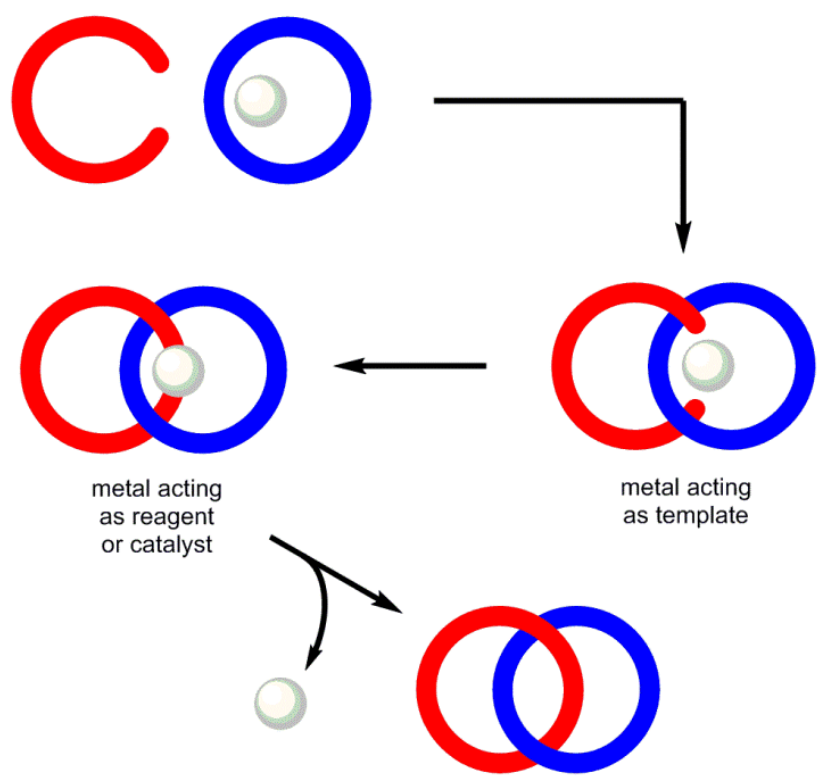

Fig. 14 Schematic representation of the active metal template synthesis of 20 a [2]catenane.

Saito et al reported the synthesis of [2]catenanes by the oxidative homocoupling of terminal diynes employing a macrocyclic $\mathrm{Cu}^{\mathrm{I}}$ phenanthroline complex and a range of terminal diynes with yields as high as 64\% (Figure 15). It is noteworthy 25 that due to the mechanism of the active metal templation strategy, each of the catenanes possess one ring devoid of coordination sites for the metal cation. ${ }^{58}$

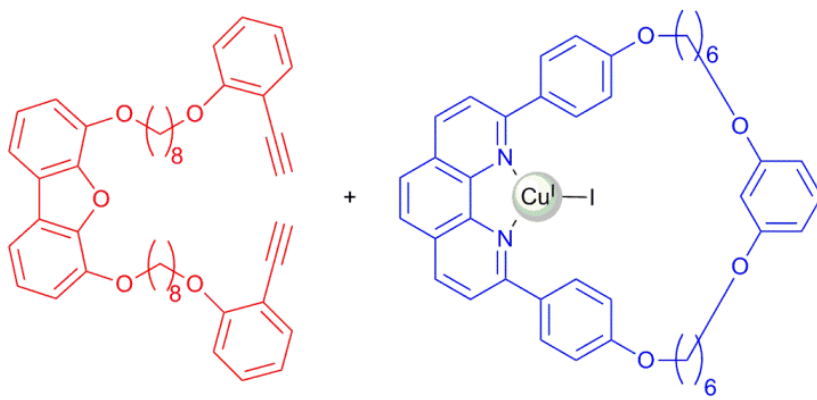

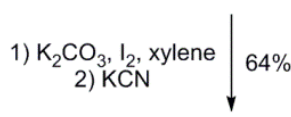

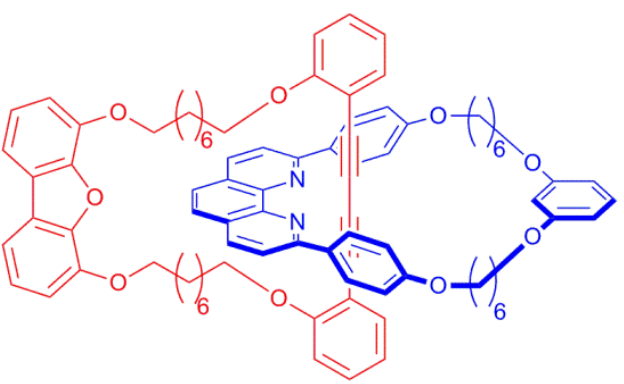

Fig. 15 Saito's active metal template [2]catenane “clipping” synthesis using Glaser coupling.

Leigh and co-workers have also prepared [2]catenanes by active metal templation by use of both Cadiot-Chodkiewicz 
coupling and the copper assisted azide-alkyne cycloaddition (CuAAC) "Click” reaction. In the latter case, [2]catenanes were prepared via "clipping” and “double clipping”, a mechanistic consequence meaning that both rings retain metal coordination 5 sites (Figure 16). ${ }^{59}$

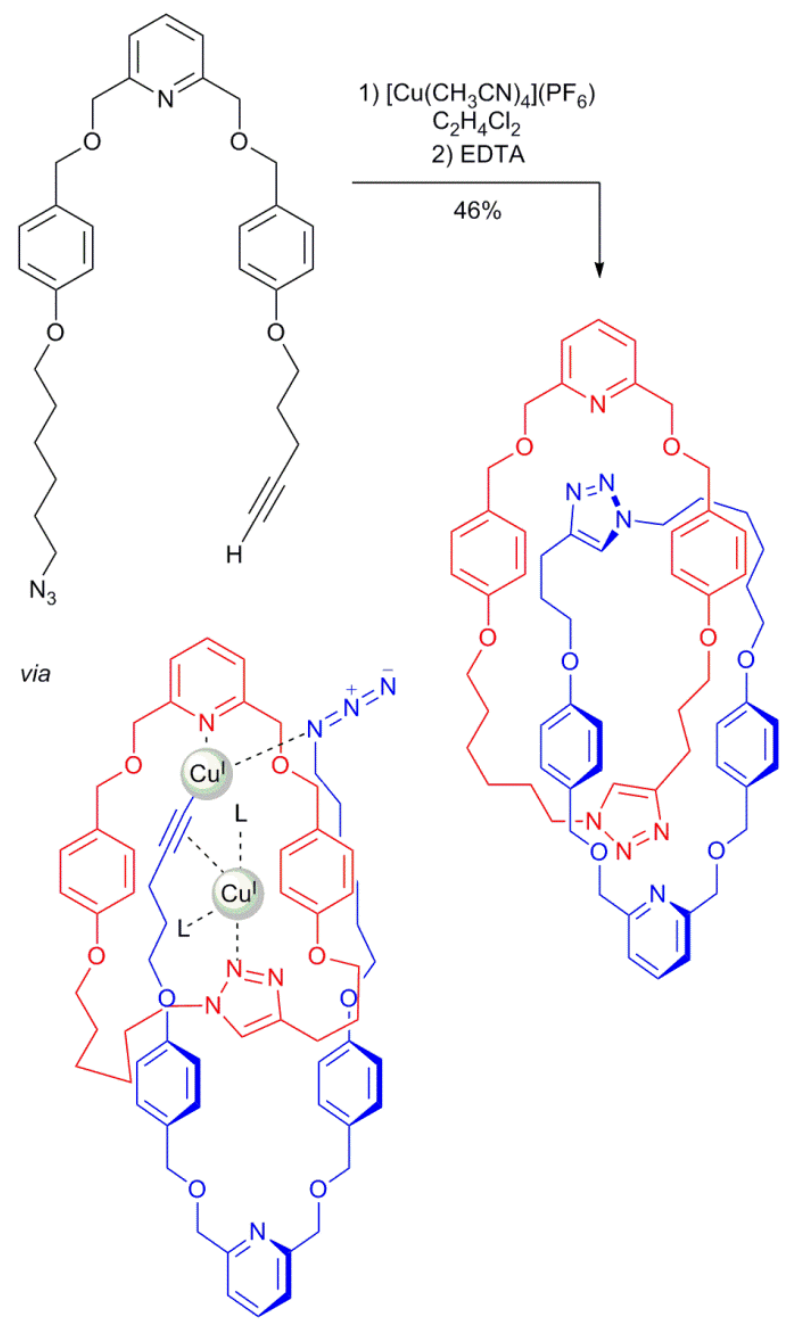

Fig. 16 Leigh's active metal template [2]catenane "double clipping” synthesis using the CuAAC reaction.

Active metal templation has been employed in the construction 10 of a remarkable [4] catenane by Anderson and co-workers. ${ }^{60}$ First, a [2]rotaxane consisting of butadiyne linked porphyrin dimers threaded through a phenanthroline containing macrocycle was prepared by active metal template directed copper mediated Glaser coupling in a yield of $61 \%$. Following deprotection of silyl 15 protected alkynes located on the zinc metalloporphyrin stoppers, cyclization by Glaser coupling (this time employing Pd catalysis) was carried out to form the [4]catenane species in $62 \%$ yield by use of a hexapyridine template coordinating to the zinc metalloporphyrin centres (Figure 17). 

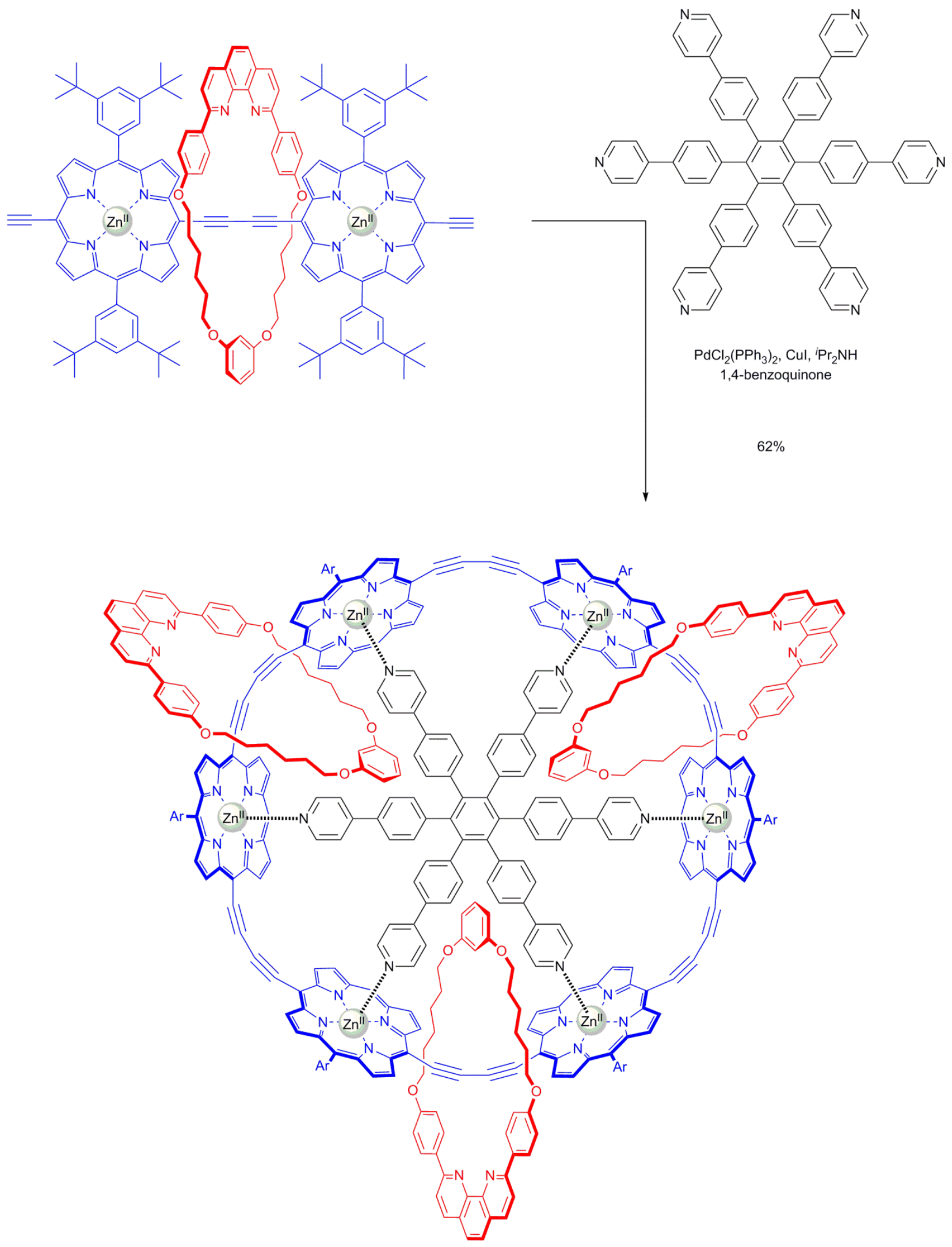

Fig. 17 Anderson's [4]catenane synthesized from an active metal templated [2]rotaxane. 


\subsection{Anions as a new class of templates for catenane synthesis}

In stark contrast to the large number of catenanes constructed by $\mathrm{Cu}^{\mathrm{I}}$ metal cation templation, no examples of anion templated catenanes were reported before 2000. A [2]catenane capable of 5 binding anions in $\mathrm{C}_{2} \mathrm{D}_{2} \mathrm{Cl}_{4}$ had been reported by Sessler and Vögtle in 1998, however, it was found that the addition of anions during the synthesis failed to increase the low yields $(<5 \%)$ of catenane formation. ${ }^{61}$ With the aim to exploit the cavities of catenanes for anion recognition and sensory applications, Beer et 10 al synthesized the first example of an anion templated [2]catenane in 2004. ${ }^{62}$ Taking note of Crabtree's report that a neutral isophthalamide will form 1:1 complexes with halides such as chloride, ${ }^{63}$ Beer and co-workers synthesized a neutral isophthalamide macrocycle through which an allyl-appended 15 methyl pyridinium chloride thread was cyclised by Grubbs' RCM to produce a [2]catenane in a yield of $45 \%$, along with small quantities $(<5 \%)$ of a [3]catenane (Figure 18a). The essential role of the chloride anion template was demonstrated by the yield of [2]catenane formation falling to $6 \%$ with bromide in place of 20 chloride, and no catenane with either iodide or hexafluorophosphate.

An alternative chloride anion templating method to generate structurally analogous catenanes has recently been reported (Figure 18b). Here a bis-amine threaded through a pyridinium 25 macrocycle is clipped with isophthaloyl dichloride. The chloride anion template that is bound in the resultant catenane is generated as a by-product of the amide condensation reaction. ${ }^{64}$ The key advantage of this new synthetic strategy is the elimination of Grubbs' catalyst, which is expensive and intolerant to certain 30 ligating functionality.

With both [2]catenanes depicted in Figure 18, exchange of the halide anion template for the non-coordinating hexafluorophosphate anion, reveals an interlocked cavity that binds chloride more strongly than either acetate or 35 dihydrogenphosphate in $1: 1 \mathrm{CDCl}_{3} / \mathrm{CD}_{3} \mathrm{OD}$, which is opposite to what is observed with the hexafluorophosphate salt of the uncyclized methyl pyridinium RCM precursor. In the same solvent system, a recently prepared bis-triazole pyridinium catenane - analogous to the bis-amide pyridinium catenane 40 synthesized by the Grubbs' ring closing metathesis method impressively bound chloride ten times more strongly than it bound dihydrogen phosphate (Figure 19). ${ }^{65}$



Fig. 19 Bis-triazole pyridinium [2]catenane that binds chloride ten times more strongly than dihydrogen phosphate in $1: 1 \mathrm{CDCl}_{3} / \mathrm{CD}_{3} \mathrm{OD}$.

(a)
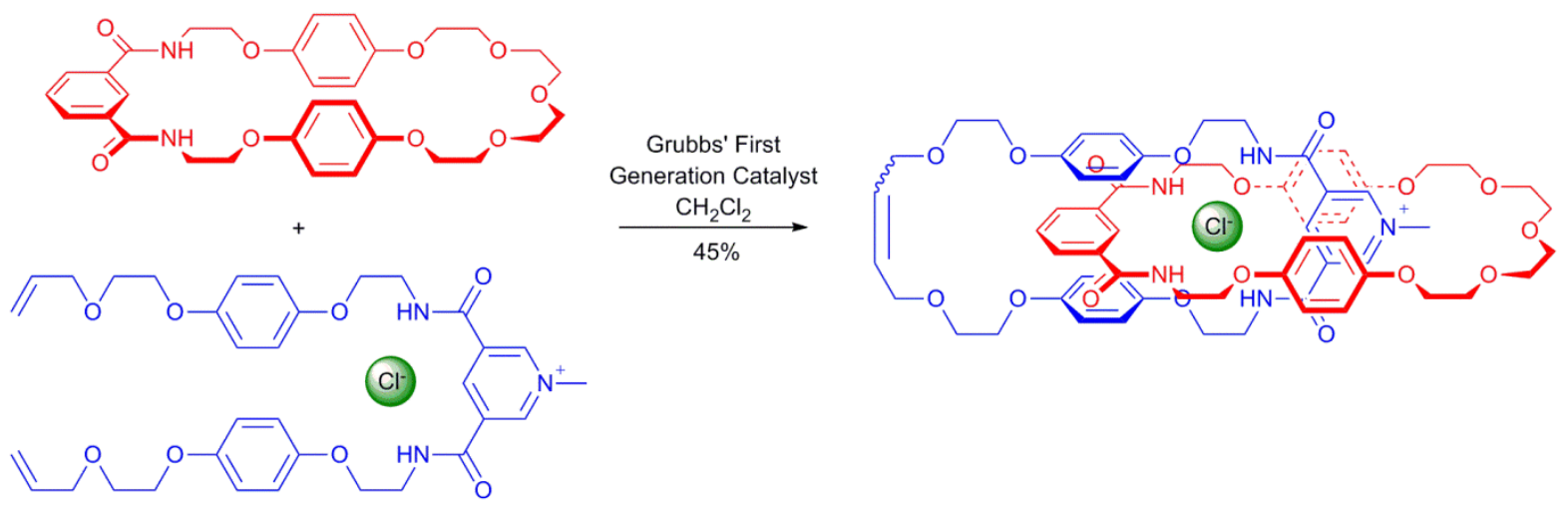

(b)
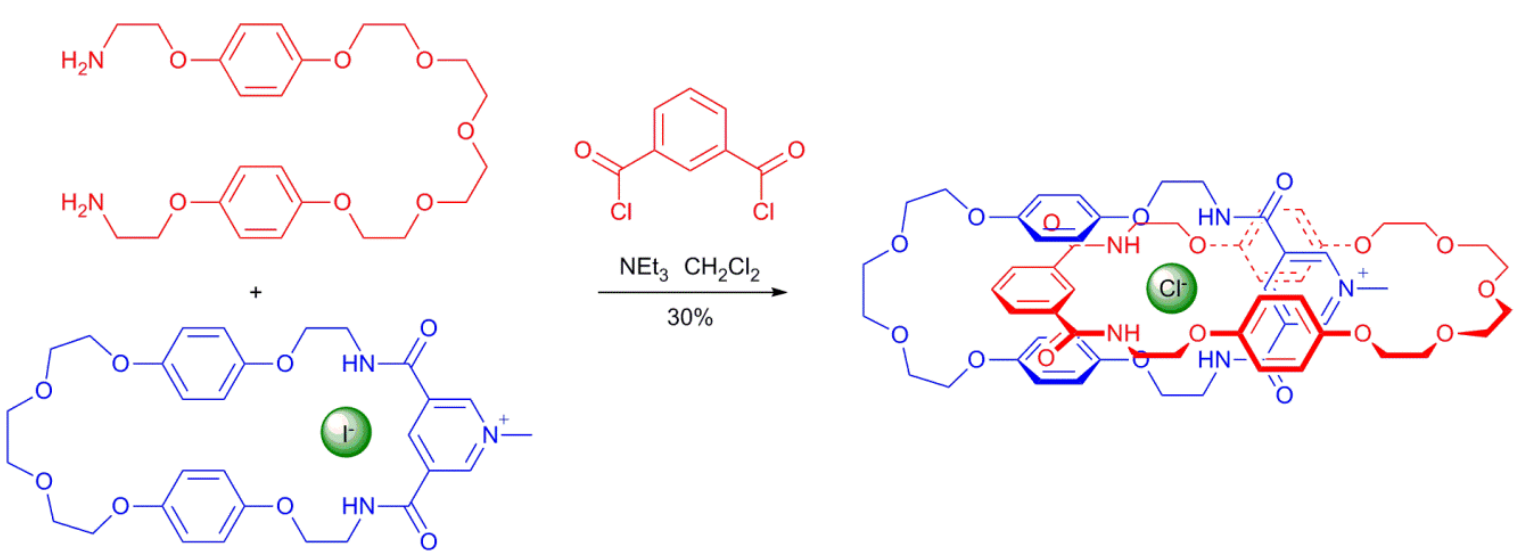

Fig. 18 Synthesis of chloride templated [2]catenanes by (a) Grubbs’ catalyzed RCM and (b) bis-amine/bis-acid chloride clipping. 
To achieve anion sensing, rather than mere binding, incorporation of an appropriate reporter group into the catenane structural framework is required. This has been accomplished by appendage of the redox-active ferrocene moiety. A characteristic 5 cathodic shift in the ferrocene/ferrocenium redox couple (i.e. stabilization of the ferrocenium oxidation state) was observed upon chloride recognition in $\mathrm{CH}_{3} \mathrm{CN} / \mathrm{CH}_{2} \mathrm{Cl}_{2}$ solution, where the maximum cathodic shift in the metallocene redox couple was observed at one equivalent of halide anion addition. In contrast, 10 for oxoanions further equivalents were required in order to attain the greatest redox couple cathodic response (Figure 20). ${ }^{66}$

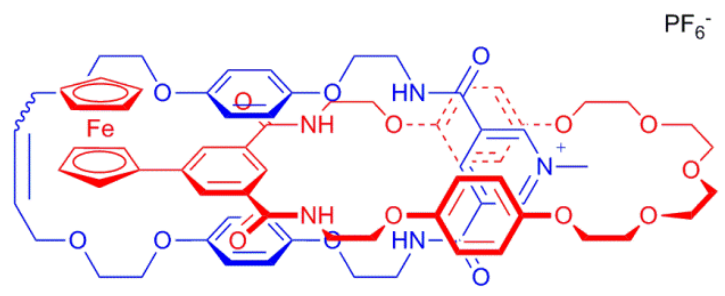

Fig. 20 Ferrocene-appended [2]catenane host system capable of electrochemical anion sensing.

15 The synthetic potential of this chloride anion templation methodology is illustrated further by the preparation of a "handcuff" catenane (Figure 21). This higher order catenane was constructed by Grubbs' catalyzed linear cross metathesis of two equivalents of a methyl pyridinium chloride precursor threaded 20 through a bis-isophthalamide "handcuff" bis-macrocycle. ${ }^{67}$ The solid-state structural determination of this species represents the first example of a crystal structure of such a catenane topology.

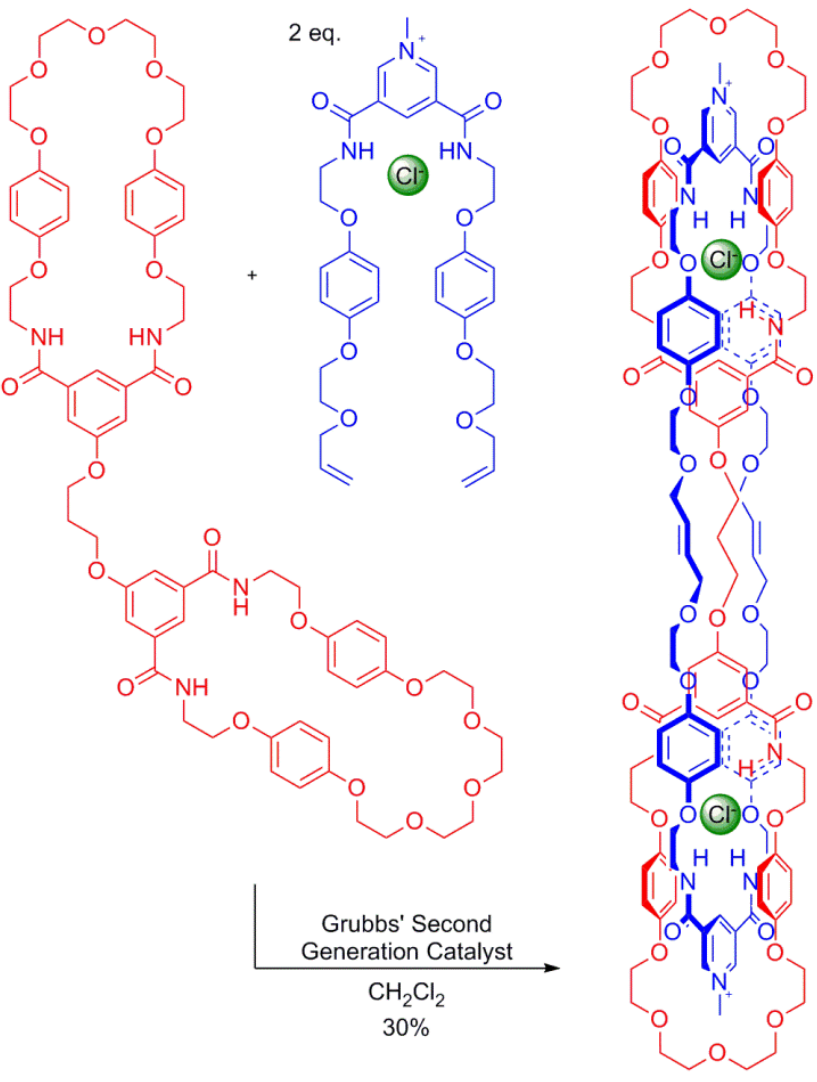

Fig. 21 Synthesis of a chloride anion templated "handcuff" catenane.
25 Anion-templated [2]catenanes have also been synthesized by use of a "double clipping” RCM strategy. A chloride-templated [2]catenane was prepared by taking one equivalent of chloride methyl pyridinium precursor and one equivalent of hexafluorophosphate methyl pyridinium precursor with Grubbs' 30 catalyst. The [2]catenane was isolated in an impressive yield of $78 \%$ (Figure 24). ${ }^{68}$ The stoichiometry of the chloride anion to pyridinium precursor is critical: cyclization of the chloride salt gave the dichloride salt of the catenane in a yield of $34 \%$, whereas cyclization of the hexafluorophosphate salt afforded the 35 dihexafluorophosophate salt in a yield of $16 \%$. Due to the double positive charge of the catenane, the dihexafluorophosphate salt of the catenane exhibits enhanced anion binding affinity compared to the monocationic catenane species above. Indeed, a [2]catenane analogous to that in Figure 22 has been shown 40 selectively to bind chloride selectively (over more basic singlycharged oxoanions) in solvent systems containing $30 \% \mathrm{D}_{2} \mathrm{O} .^{69}$

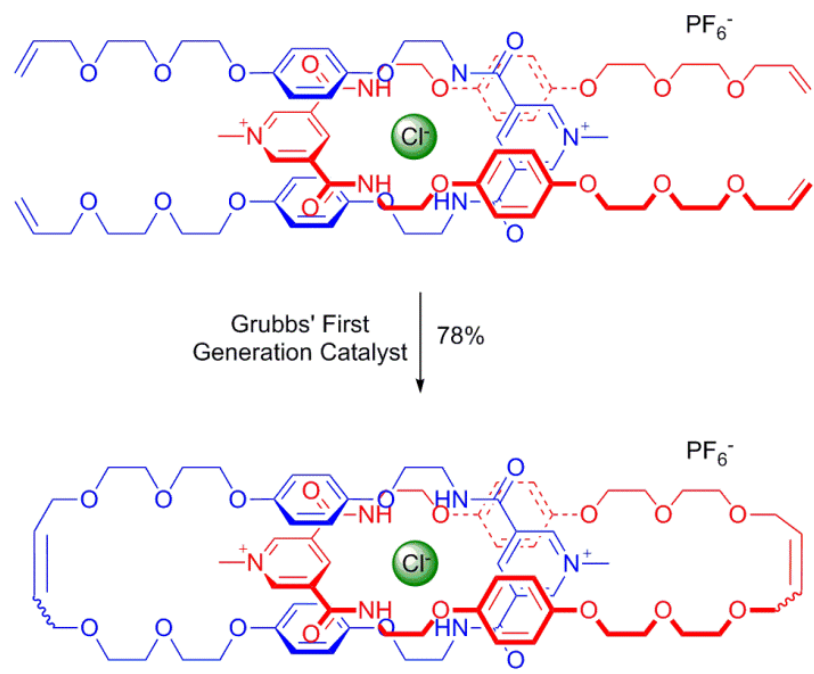

Fig. 22 Synthesis of chloride templated [2]catenane by "double clipping”.

The dianion sulfate has also been shown to be a highly 45 efficient template for catenane formation: double cyclization of a pyridinium nicotinamide thread around a sulfate anion produced a [2]catenane in $80 \%$ yield, which after sulfate removal was found to selectively bind the templating oxodianion (Figure 23). ${ }^{70}$

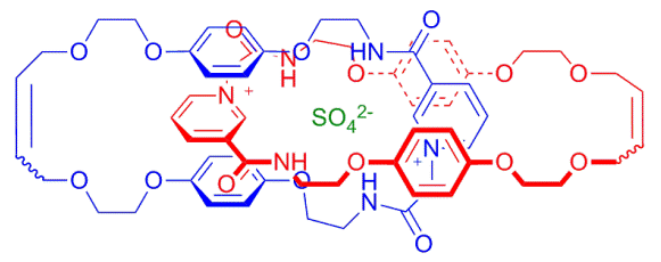

50 Fig. 23 A sulfate templated [2]catenane prepared by “double clipping”.

Neutral indolocarbazole ligands have been employed to template the formation of chloride templated [2]catenanes. Jeong described the Grubbs' catalyzed RCM double cyclization of two neutral indolocarbazole motifs around a chloride anion; the 55 resulting [2]catenane was found to be chloride selective (Figure 24). ${ }^{71} \mathrm{Li}$ and $\mathrm{Li}$ have also reported upon the preparation of a similar catenane, with comparable binding properties, prepared utilizing the CuAAC "Click" reaction. ${ }^{72}$ 


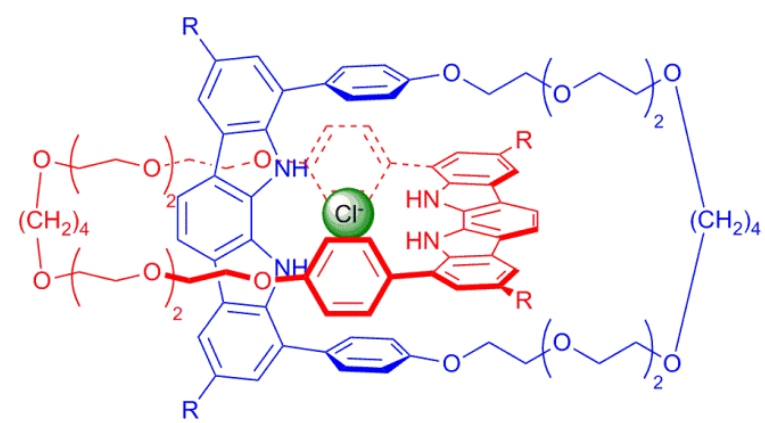

Fig. 24 An indolocarbazole containing [2]catenane that acts as a selective host for chloride anions.

In a notably different way of including an anionic template, 5 Brad Smith's group have prepared a set of squaraine [2]catenanes (Figure 25). ${ }^{73}$ They exhibit bright, deep-red fluorescence and remarkably high chemical stability, this latter feature being attributed to the squaraine's encapsulation within the interlocked structure preventing nucleophilic attack by polar organic solvents.
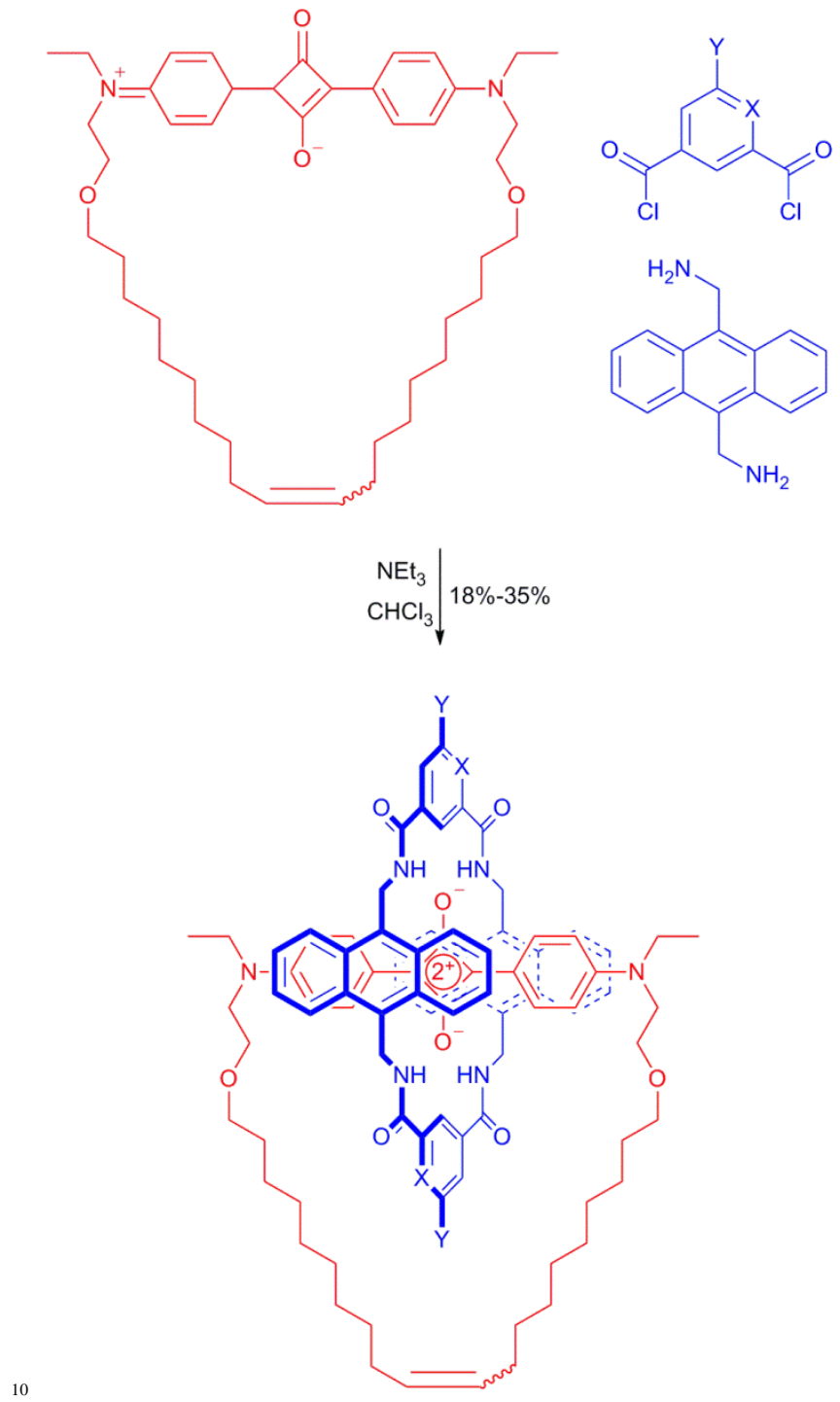

Fig. 25 Synthesis of squaraine [2]catenanes.

\subsection{Use of alternative supramolecular interactions in catenane synthesis: halogen bonding and radical templation}

Chemists continue to investigate alternative templates and 15 templating interactions in order to construct catenanes. Here, we highlight the use of two classes of supramolecular interaction which have only very recently been employed in catenane synthesis: halogen bonding and radical templation.

Halogen bonds, which can be represented by Y-X $\cdots$ D, where ${ }_{20} \mathrm{X}$ is an electrophilic halogen atom, D is a donor of electron density and $\mathrm{Y}$ is another atom (e.g. $\mathrm{C}$ or $\mathrm{N}$ ), arise from the appearance of a $\sigma$-hole at the $\mathrm{X}$ end of the $\mathrm{Y}$-X bond, into which electron density may be donated. As the electron deficient region sits on the halogen $\mathrm{X}$ pole of the $\mathrm{Y}-\mathrm{X}$ bond, the halogen bond, ${ }_{25}$ like hydrogen bonding, is highly directional. ${ }^{74,75}$

In conjunction with anion templation, halogen bonding was first used in the construction of a [2]catenane by Beer et al (Figure 26). ${ }^{76}$ In an analogous method to the catenane synthesis in Figure 22, the catenane was prepared by cyclising two 30 equivalents of a bis-bromoimidazolium macrocycle precursor around a bromide anion template. The bis-hexafluorophosphate salt of the catenane was demonstrated to exclusively bind chloride and bromide in acetonitrile by fluorescence spectroscopy.



Fig. 26 An anion templated, halogen bonding [2]catenane.

A related catenane has since been prepared, where in place of an anion template, the lone pair of a pyridyl motif integrated into a macrocycle donates electron density to the halogen iodine atom 40 of an iodo-pyridinium thread (Figure 27). ${ }^{77}$ While only isolated in modest yield (61/2\%), this is still an impressive result considering only a single (charged assisted) halogen bond is being used to template catenane formation.

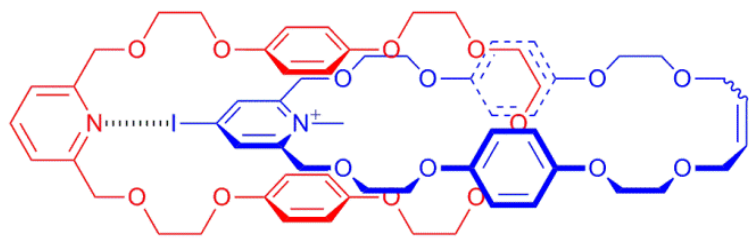

45 Fig. 27 A [2]catenane templated by a single charge assisted halogen bond.

The use of favourable radical-radical interactions to synthesize a [2]catenane was reported recently by Stoddart and co-workers (Figure 28) ${ }^{78}$ Reducing a 4, 4'-bis-pyridinium bis-bromo xylene precursor (dissolved in acetonitrile), allows for the formation of 50 radical cations, which then associate into a dimer. Double clipping with 4, 4'-bipyridine generates a homo-catenane, which under the reducing reaction conditions, is formed with each bipyridine unit being a radical cation (i.e. the catenane is tetracationic upon formation). In ambient air, oxidation of the 55 catenane to a mixture of the di- and mono-radical occurs; full oxidation to the octacationic, non-radical catenane is achieved 
using a radical oxidising agent. It has been disclosed that the isolated catenane may be reversibly switched (chemically and electrochemically) between six redox states $(0,2+, 4+, 6+, 7+$ and $8+$ ), with both the mono-radical $(7+)$ and non-radical $(8+)$ 5 being air stable.



Fig. 28 Synthesis of a catenane by radical templation.

\subsection{Thermodynamically controlled catenane synthesis}

So far in this review, the catenane syntheses can be considered to 10 have been under kinetic control.§ However, application of thermodynamically controlled synthesis offers a key advantage, for the reversal of a synthetic "mistake", for example a cyclization that leads to the formation of a non-interlocked macrocycle, may be undone and "corrected". In addition, 15 thermodynamically controlled synthesis offers the potential for a third kind of catenane synthesis, in addition to "clipping" and "double clipping”, specifically that of magic ring synthesis. Here at least one of two preformed rings opens, then an appropriate self-assembly event occurs such that ring closure affords an 20 interlocked catenane.

There are two distinct classes of thermodynamically controlled reactions: (a) reversible metal-ligand coordinate bond and (b) reversible covalent bond formation. The latter of these is alternatively known as dynamic covalent chemistry, which can 25 lead to confusion with the related concept of dynamic combinatorial chemistry (and its associated dynamic combinatorial libraries), for both of these have been abbreviated to "DCC". To avoid confusion here we have chosen not to use the acronym "DCC" in this review.

\subsubsection{Reversible metal-ligand coordinate bond formation}

Along with their use as (passive and active) templates based on their coordination properties, metal cations have also been incorporated into catenanes as integral parts of the macrocyclic 35 rings. This is exemplified by the archetypal demonstration of "magic ring" synthesis by Fujita and co-workers. ${ }^{79-81} \mathrm{Pd}^{\mathrm{II}}$ containing macrocycles were found to form [2]catenanes in aqueous solution, driven by the hydrophobic effect (Figure 29). The choice of metal is critical: using the third row $\mathrm{Pt}^{\mathrm{II}}$ cation, in 40 place of the second row $\mathrm{Pd}^{\mathrm{II}}$ cation, leads to a system where the ratios of macrocycle and catenane are frozen at room temperature, i.e. this system, at room temperature, is kinetically locked and the system is not under thermodynamic control.
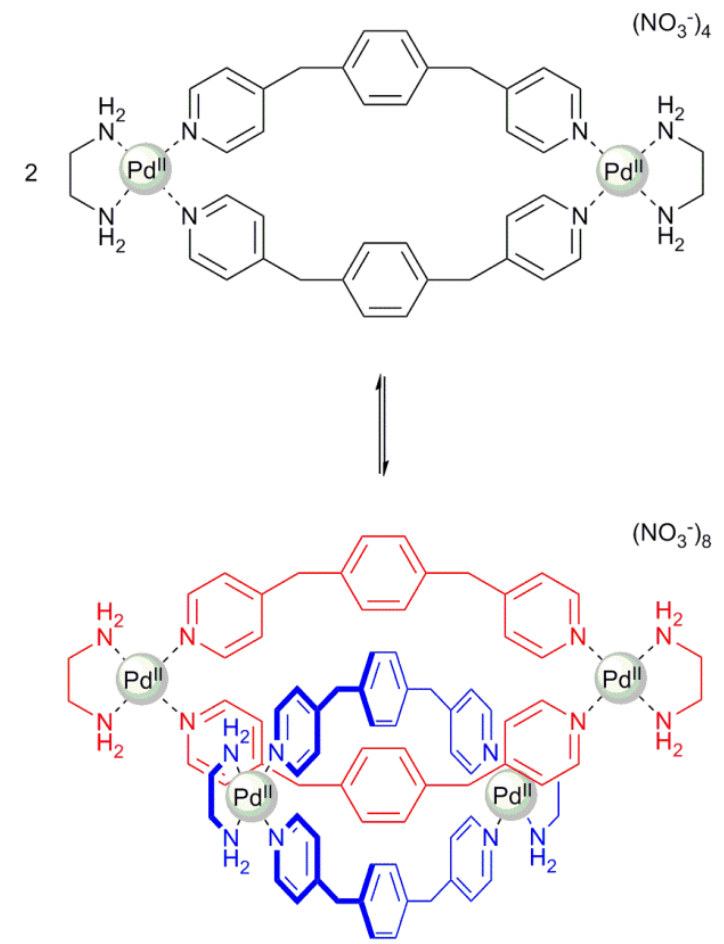

$45 \quad$ Fig. 29 Fujita’s seminal "magic ring” synthesis of a [2]catenane.

The use of this particular Pd" cation-enamine "corner" motif has proved popular in the construction of other self-assembled metal-organic catenanes. For example, Quintela and co-workers have used it to prepare [2]- and [3]-catenanes, in conjunction with 50 4, 4'-bipyridinium containing ligands and electron rich crown ether macrocycles (Figure 30). ${ }^{82-84}$

Beer and co-workers have reported upon an alternative, serendipitously discovered, magic ring synthesis. The addition of $\mathrm{NaReO}_{4}$ as an oxidant to a dinuclear $\mathrm{Cu}^{\mathrm{II}}$ dithiocarbamate 55 macrocycle, leads to the formation of $\mathrm{Cu}^{\mathrm{III}}$. The kinetically labile $\mathrm{Cu}^{\mathrm{II}}$ dithiocarbamate coordinate bond allows for the ring opening of a dinuclear $\mathrm{Cu}^{\mathrm{II}}$ dithiocarbamate macrocycle, whereupon favourable $\mathrm{Cu}^{\mathrm{II}}$-dithiocarbamate-Cu${ }^{\mathrm{III}}$-dithiocarbamate donoracceptor interactions result in formation of a mixed valence ${ }_{60} \mathrm{Cu}^{\mathrm{II}} / \mathrm{Cu}^{\mathrm{III}}$ catenane (Figure 31). ${ }^{85}$ An analogous heteropolymetallic $\mathrm{Cu}^{\mathrm{II}} / \mathrm{Au}^{\mathrm{III}}$ catenane was subsequently prepared by using homodimetallic $\mathrm{Cu}^{\mathrm{II}}$ and $\mathrm{Au}^{\mathrm{III}}$ dithiocarbamate macrocycles. With the $\mathrm{Au}^{\mathrm{III}}$ dithiocarbamate coordinate bond being kinetically non-labile, the catenane was formed by the 65 reversible dissociation of the labile $\mathrm{Cu}^{\mathrm{II}}$ dithiocarbamate bond. ${ }^{86}$ 
<smiles>O=S(=O)(O)C[n+]1ccc(-c2ccncc2)cc1</smiles><smiles>c1cc2ccc1OCCOCCOCCOCCOc1ccc(cc1)OCCOCCOCCO2</smiles>

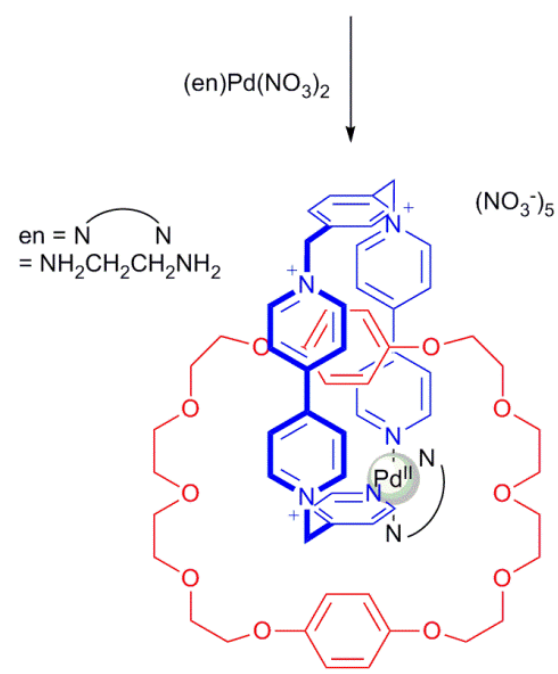

Fig. 30 Quintela's synthesis of a [2]catenane employing coordination of a $\mathrm{Pd}^{\mathrm{II}}$ cation to achieve ring closure.

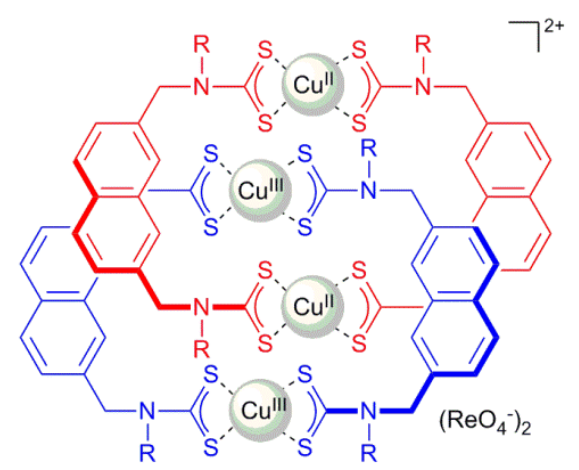

Fig. 31 Structure of Beer's $\mathrm{Cu}^{\mathrm{II}} / \mathrm{Cu}^{\mathrm{III}}$ dithiocarbamate catenane.

More recently, Wisner demonstrated that two equivalents of a bis-isophthalamide, bis-pyridyl ligand could, upon the addition of $\mathrm{PdCl}_{2}$, assemble into a [2]catenane, templated by both the $\mathrm{Pd}^{\mathrm{II}}$ cation and $\mathrm{Cl}^{-}$anion (Figure 32). ${ }^{87}$ Dissolution in a more 10 competitive solvent (e.g. $d_{6}$-DMSO) leads to the system reconstituting itself so only the macrocycle exists, however, subsequent re-dissolution in $\mathrm{CDCl}_{3}$ allows for the re-formation of the catenane by a magic ring synthetic pathway.

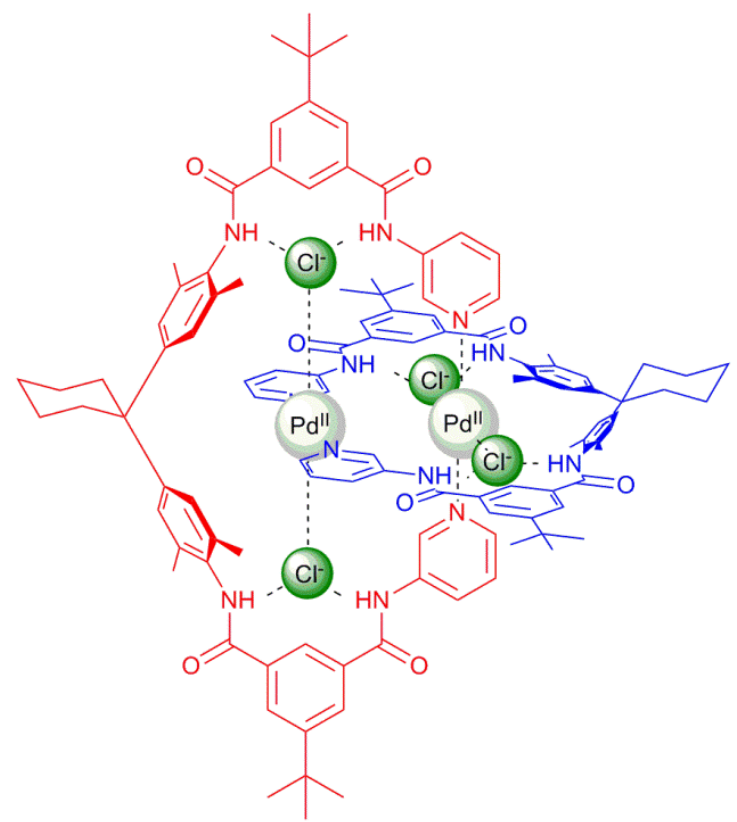

15

Fig. 32 Structure of Wisner's $\mathrm{Pd}^{\mathrm{II}}$ and $\mathrm{Cl}^{-}$templated catenane.

\subsubsection{Reversible covalent bond formation (or dynamic covalent chemistry)}

$\mathrm{Li}$ and co-workers have demonstated the use of dynamic disulfide bond chemistry to synthesize a catenane (Figure 33). ${ }^{88}$ Upon 20 acetyl deprotection only a catenane, where each ring contains two perylene units, and its constituent macrocycle are isolated after quenching the reaction, which is attributed to only these molecules being able to $\pi$-stack in the most favourable conformation.

25 The use of Grubbs' catalyst to achieve reversible olefin metathesis, and hence catenane formation by magic ring synthesis has been exemplified by Grubbs and Stoddart. ${ }^{89}$ The templating motif employed is based on a well-established crown etherdibenzylammonium ion recognition motif, and involves adding

30 Grubbs' catalyst to a solution of a crown ether containing a $\mathrm{C}=\mathrm{C}$ bond and a dibenzylammonium macrocycle (Figure 34). As Grubbs' catalysts are prone to "death" by oxidation strictly deoxygenated conditions have to be used to achieve catenane formation.

35 Nitschke et al reported the reaction of phenanthroline bisaldehyde with a phenyl containing bis-amine, that led to formation of a [2]catenane, where unusually two $\mathrm{Cu}^{\mathrm{I}}$ cations templated interlocked structure formation (Figure 35). ${ }^{90}$ In a similar vein, Lindoy and co-workers used a bis-aldehyde 40 substituted 2, 2'-bipyridyl to template [2]catenane formation, this time with a single $\mathrm{Cu}^{\mathrm{I}}$ cation template (Figure 36). ${ }^{91}$ The assembly of the catenane was believed to be quantitative (as determined by ${ }^{1} \mathrm{H}$ NMR spectroscopy), however, the subsequent trapping of the catenane by reduction of the imine bonds (not ${ }_{45}$ shown) proved problematic, resulting in a low (7\%) isolated yield. 


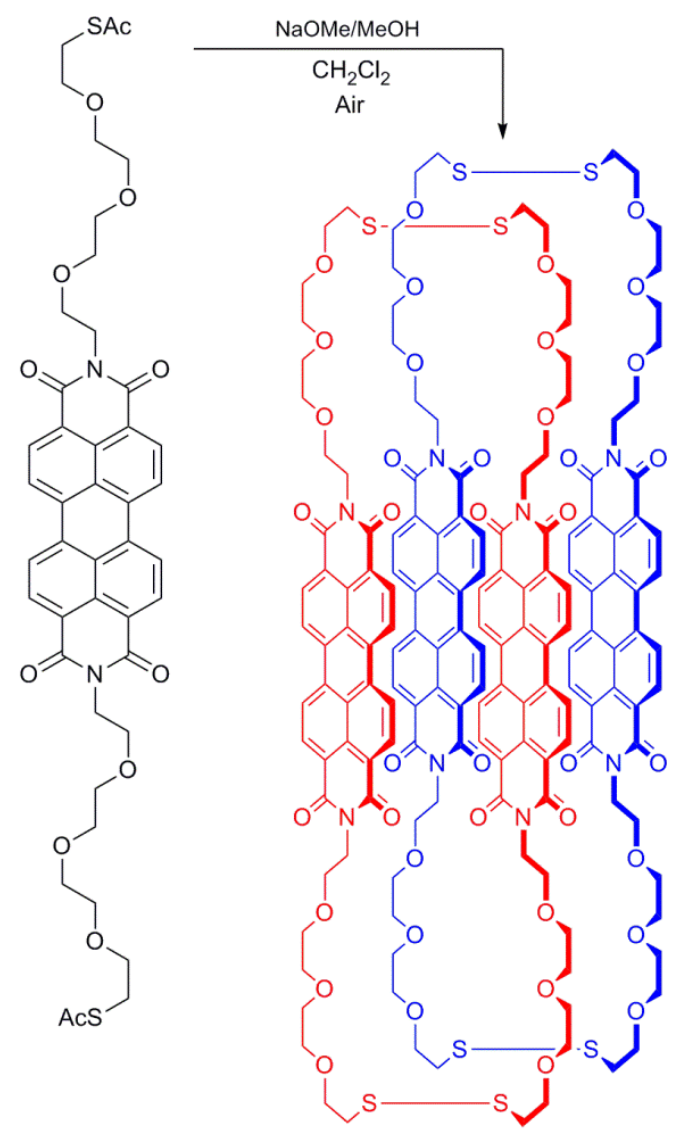

Fig. 33 Li’s neutral $\pi$-stacked perylene catenane.
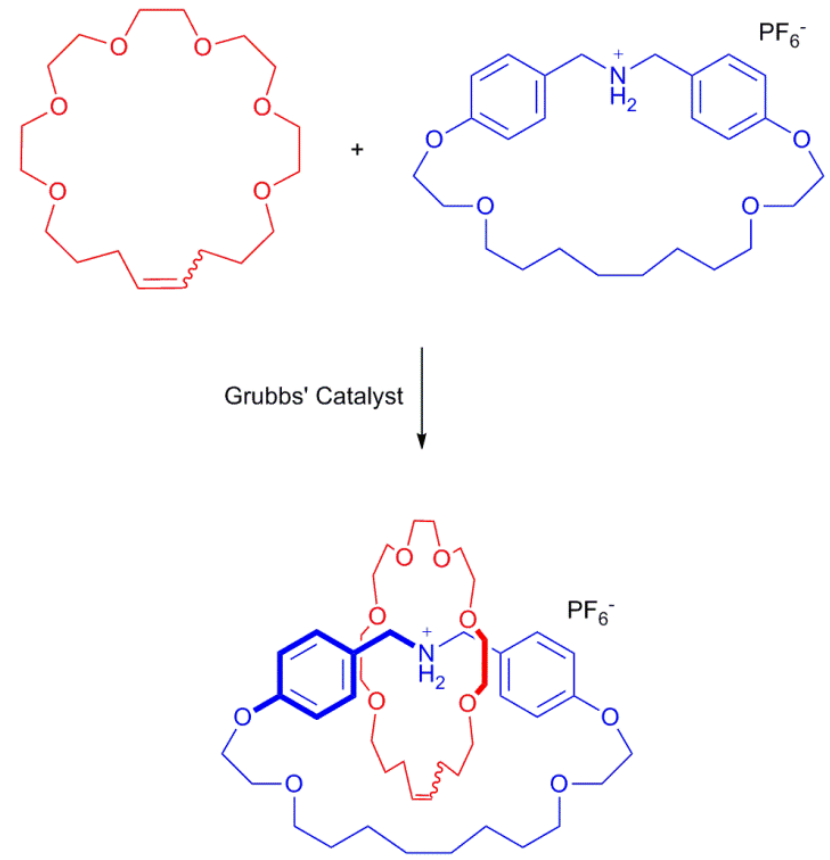

Fig. 34 Magic ring synthesis of a crown ether-dibenzylammonium catenane facilitated by Grubbs’ ring closing metathesis catalysis.

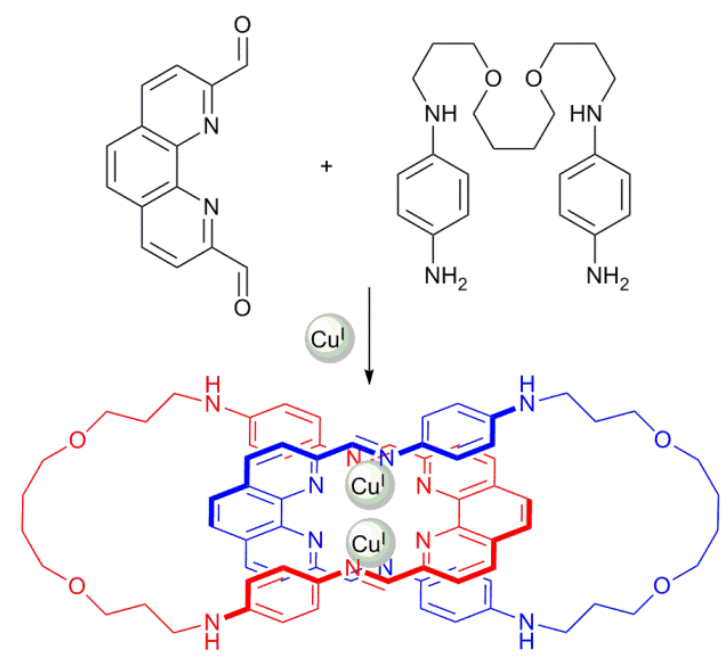

Fig. 35 Nitschke's $\mathrm{Cu}^{\mathrm{I}}$ cation templated [2]catenane generated using reversible imine formation.

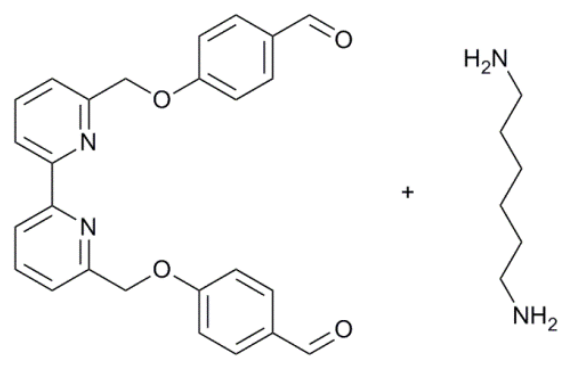

Cul

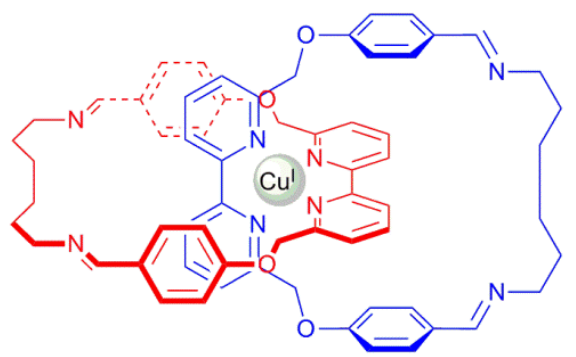

Fig. 36 Lindoy's $\mathrm{Cu}^{\mathrm{I}}$ cation templated [2]catenane generated using reversible imine formation.

The Stoddart laboratories have described the use of catalytic iodide to ring open the $\mathrm{CBPQT}^{4+}$ macrocycle, allowing for the 15 generation of [2]catenanes ${ }^{92}$ and [3] catenanes $^{93}$ (Figure 37). The strained nature of the "box"-like macrocycle, together with the facile leaving group ability of pyridine, and the subsequent stabilizing feature of the aromatic donor-acceptor interactions in the resulting catenanes, leads to impressive yields of the 20 interlocked products. 

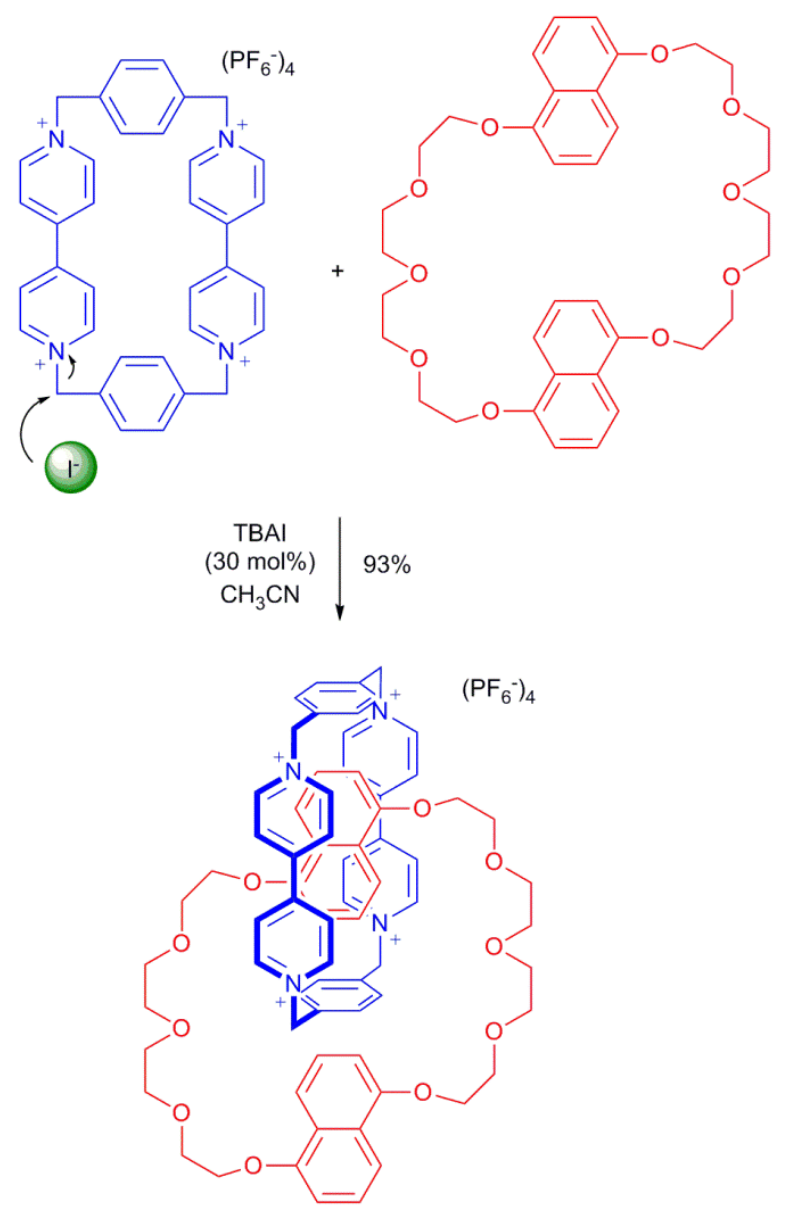

Fig. 37 Use of iodide to catalyse the magic ring synthesis of an aromatic donor-acceptor [2]catenane (nucleophilic attack of iodide on CBPQT ${ }^{4+}$ macrocycle depicted).

\section{3.4.3 Dynamic combinatorial libraries}

If the starting materials of a reaction system can reversibly form more than one bond, then a dynamic combinatorial library (or DCL) is formed. Selection of appropriate starting materials should enable the generation of a large library, with a number of 10 different products being created. If many products are formed, then the addition of a template may lead to the components reassembling to minimize the total energy of the library, and possibly lead to the amplification of a single product. To date, substrates capable of forming imines and disulfides are the 15 reactions of choice for DCLs, because they can exchange rapidly, using synthetically unchallenging reaction conditions and they can be readily "switched off" to allow for product isolation.

The application of dynamic combinatorial chemistry in the preparation of catenanes was first demonstrated by Sanders and ${ }_{20}$ Otto. This library contained peptide building blocking appended with (masked) aldehyde and hydrazine functionality, to allow for the reversible formation of hydrazones. Without an additional template, a series of macrocycles were formed, but in the presence of acetylcholine, amplification of a [2]catenane (where 25 each ring contained three peptide building blocks) occurred (Figure 38) ${ }^{94}$ It was possible to isolate a single diastereomer of the catenane from the library in a yield of $67 \%$. The free catenane has a broad ${ }^{1} \mathrm{H}$ NMR spectrum (in 95:5 $\mathrm{CDCl}_{3} / d_{6}$-DMSO), but upon the addition of acetylcholine, the spectrum sharpened,
30 indicative of binding of the neurotransmitter by the catenane.

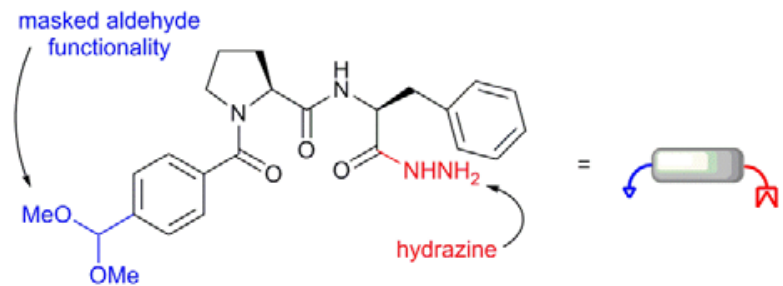

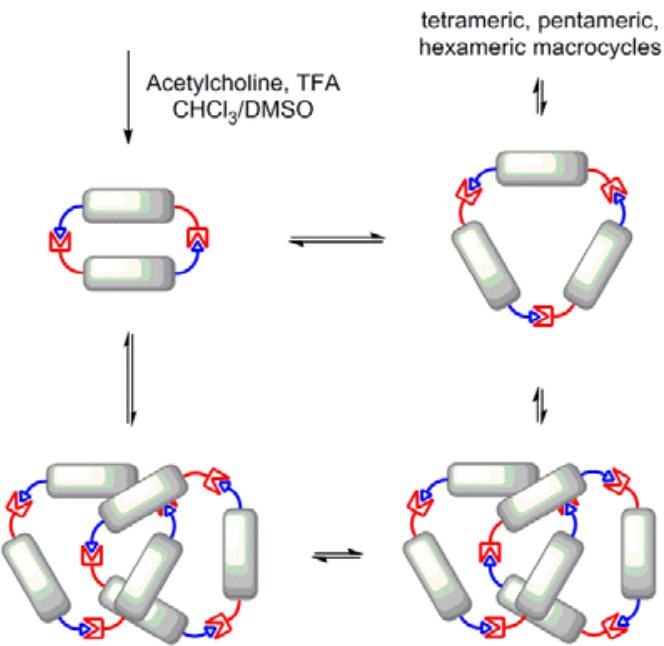

Fig. 38 Synthesis of an acetylcholine-templated peptidic [2]catenane by dynamic combinatorial chemistry (only one of the two catenane diastereoisomers that are depicted were formed).
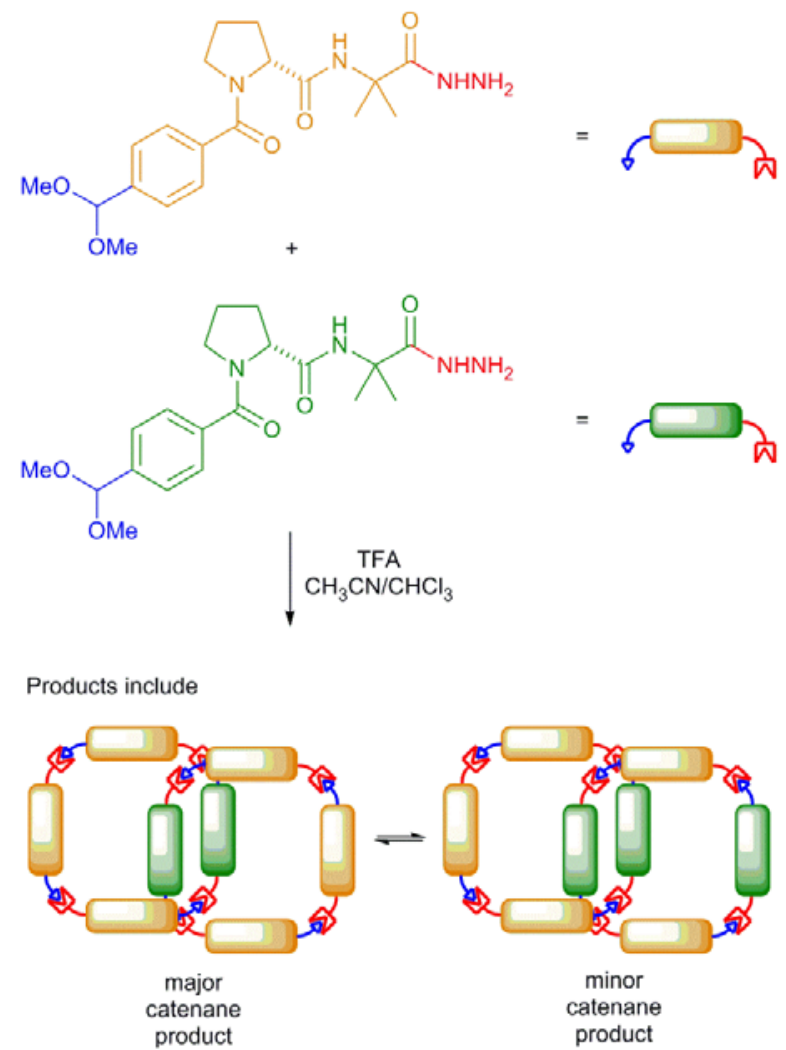

Fig. 39 Synthesis of further peptidic [2]catenanes by use of dynamic combinatorial library (isomerism of the two catenane species ignored for clarity). 
Gagné and co-workers have subsequently shown that by subtly varying the structure of the peptide building block, the formation of two [2]catenanes, with interlocked rings consisting of four peptide building blocks each, occurs in the absence of 5 acetylcholine (Figure 39). ${ }^{95-97}$ In the major catenane product, the requirement for the substituent $\mathrm{R}$ to be an aromatic group infers that intercalation of this ring between a proline and 2-aminoisobutyric acid serves as a driving force for catenane stabilization - a hypothesis corroborated by single crystal X-ray 10 crystallography of an isolated [2]catenane. Generally, intra- and intermacrocyclic hydrogen bonds, $\pi-\pi$ and $\mathrm{CH}-\pi$ stacking are considered to be the templating interactions favouring formation of these catenanes.<smiles>O=C(O)C(CS)N1C(=O)c2ccc3c4c(ccc(c24)C1=O)C(=O)N(C(CS)C(=O)O)C3=O</smiles>

$+$<smiles>O=C(CCCOc1cccc2c(OCCCC(=O)N[C@@H](CS)C(=O)O)cccc12)N[C@@H](CS)C(=O)O</smiles>

$$
\downarrow \frac{\mathrm{O}_{2}, \mathrm{pH}_{2} 8}{\mathrm{H}_{2} \mathrm{O}}
$$

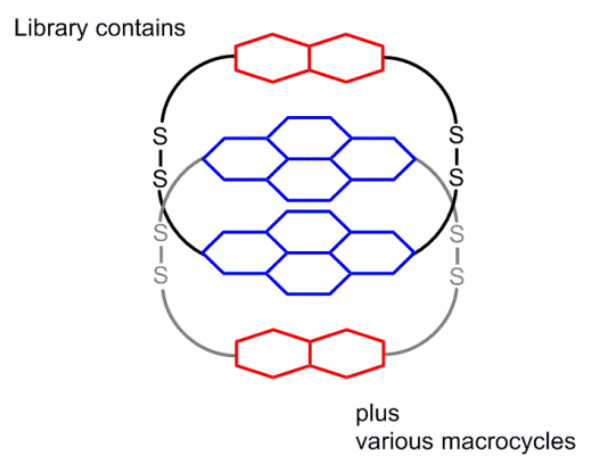

15

Fig. 40 Preparation of a D-A-A-D [2]catenane by use of dynamic combinatorial chemistry.

Sanders and Pantoş have extensively studied dynamic combinatorial libraries consisting of electron-poor naphthalenediimide acceptor (A) and electron-rich naphthalene 20 donor (D) building blocks. ${ }^{98-104}$ In these libraries the two sets of building blocks are appended with thiols to allow for reversible disulfide formation. In their first reported dynamic combinatorial library, isolation of a new type of neutral "donor-acceptor" [2]catenane was achieved where both complementary units were 25 in the same macrocycle and an unprecedented D-A-A-D stacking of the aromatic groups was observed (Figure 40). ${ }^{98}$ It was possible to enhance the yield of catenane formation by not only increasing the concentration of building blocks, but also increasing the ionic strength of the library solution, which favours 30 the burying of the hydrophobic aromatic surfaces within a catenane structure. It was also reported that addition of an electron-rich template to the library increased catenane formation, attributed to the molecule being suitable for intercalation between the electron poor naphthalenediimide units in the centre of the 35 catenane structure.

In subsequent studies the ability of dynamic combinatorial chemistry to generate further unexpected structures was evident. For example, [2]catenanes containing D-A-D-D, ${ }^{99,101,102}$ D-A-A$\mathrm{D},{ }^{100} \mathrm{~A}-\mathrm{D}-\mathrm{A}-\mathrm{A}^{102}$ and even A-A-A-A ${ }^{104}$ arrangements of 40 aromatic units have been identified in libraries. By incorporation of two naphthalenediimides in a single electron acceptor unit, a [3]catenane, exhibiting traditional D-A-D-A stacking, was also prepared. ${ }^{103}$ However, the generation of so many catenane species not possessing a D-A-D-A arrangement of aromatic units, implies 45 that hydrophobicity plays a very important role in the template synthesis of these molecules.

\section{Catenanes that behave as "molecular machines"}

Molecular machines, molecules exhibiting controlled switchable behaviour, have been highly prized as they may be 50 potential components of so-called "molecular computers". A "molecular machine”, as defined by Kay, Leigh and Zerbetto, is a chemical species where a "stimulus controlled, large amplitude or directional mechanical motion . . . results in a net task being performed". ${ }^{18}$ The same authors state that a molecule may be 55 regarded as a motor when motion is a function of trajectory, whereas it is simply a switch if motion is a function of state, i.e. reversal of the motion undoes any mechanical effect. Here we provide a review of catenanes that may be classified as molecular switches, before covering a couple of rare examples of catenanes 60 that may be regarded as motors.

\section{1 “Molecular switch” catenanes}

\subsubsection{Redox-induced switching}

An early example of a catenane molecular switch was reported by Sauvage. ${ }^{105}$ The hetero-[2]catenane incorporates a macrocycle 65 containing both phenanthroline and terpyridine moieties, and a macrocycle possessing only phenanthroline. Re-arrangement of the interlocked rings could be triggered electrochemically, with the motion being driven by the different coordination preferences of the $\mathrm{Cu}^{\mathrm{I}} / \mathrm{Cu}^{\mathrm{II}}$ oxidation states of the complexed cation: 70 tetrahedral for $\mathrm{Cu}^{\mathrm{I}}$ and 5-coordinate for $\mathrm{Cu}^{\mathrm{II}}$ (Figure 41). A related homo-[2]catenane where each ring possesses both phenanthroline and terpyridine groups, was subsequently found to undergo much faster switching from 4-coordinate $\mathrm{Cu}^{\mathrm{I}}$ to 6coordinate $\mathrm{Cu}^{\mathrm{II}}$ via a 5-coordinate $\mathrm{Cu}^{\mathrm{II}}$ intermediate. ${ }^{106}$ 

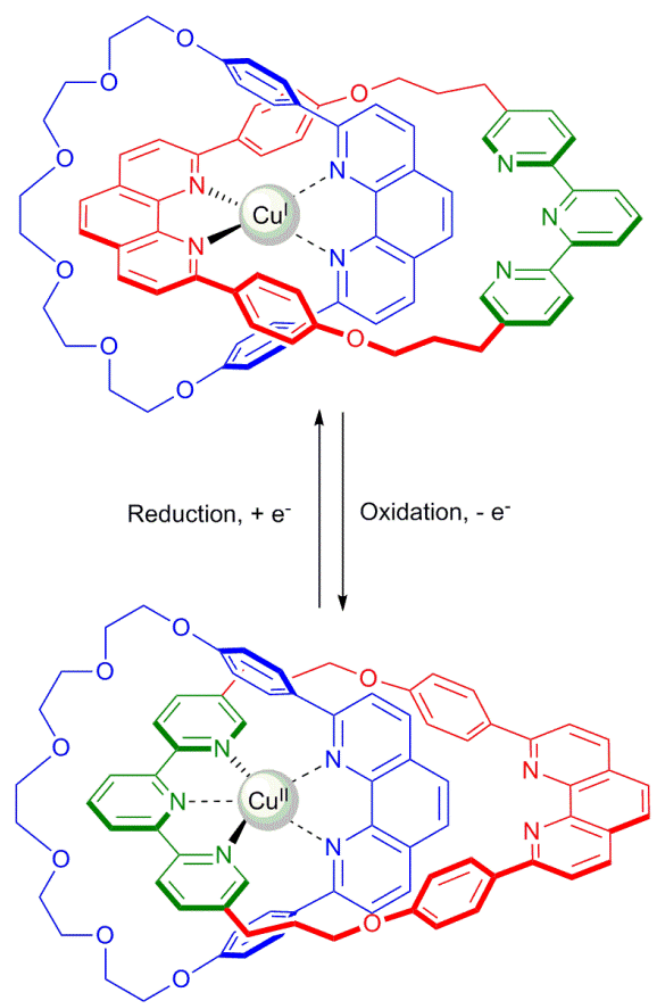

Fig. 41 Sauvage’s electrochemically triggered “pirouetting” of a hetero[2]catenane.
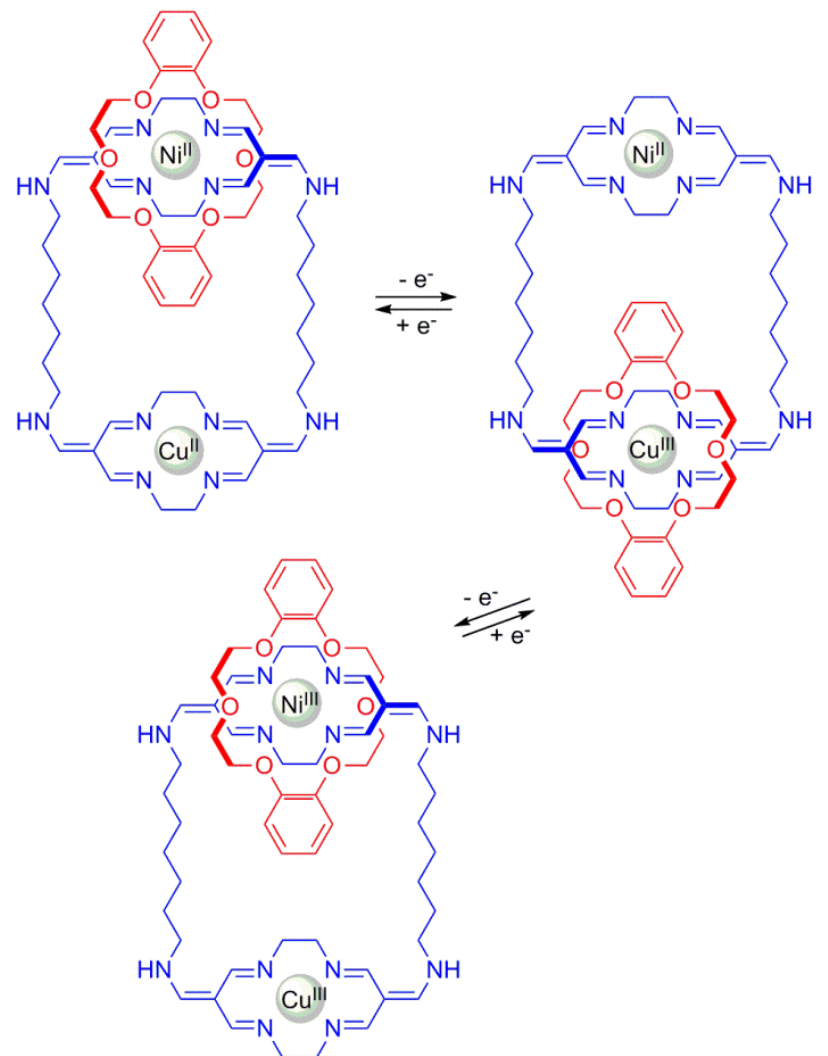

Fig. 42 A redox-switchable dual cation containing [2]catenane.

Electrochemical switching has also been observed in a dual metal cation containing catenane (Figure 42). ${ }^{107} \mathrm{~A}$ cyclic crown ether ring resides over the $\mathrm{Ni}^{\mathrm{II}}$ centre, however, if the $\mathrm{Cu}^{\mathrm{II}}$ centre is oxidized to $\mathrm{Cu}^{\mathrm{III}}$, then the crown ether will move to this centre. ${ }_{10}$ Subsequent oxidation of $\mathrm{Ni}^{\mathrm{II}}$ results in the crown ether moving back to its original site.

The group of Stoddart has prepared a redox-switchable catenane containing the electron-poor $\mathrm{CBPQT}^{4+}$ macrocycle stationed over an electron-rich tetrathiafulvalene (TTF) unit ${ }_{15}$ (Figure 43). ${ }^{108}$ Oxidation of the TTF motif (either electrochemically or chemically), causes the macrocycle to switch to reside over the naphthalene unit which is more electronrich than the $\mathrm{TTF}^{2+}$ di-cation. This reversible event was accompanied by notable changes in colour: dark green (TTF) and 20 maroon $\left(\mathrm{TTF}^{2+}\right)$.


Fig. 43 Stoddart's TTF [2]catenane exhibiting redox-controlled pirouetting.

More recently, the same group has combined donor-acceptor 25 and radical-radical interactions in switchable [2]catenanes. ${ }^{109}$ Prepared in their ground states, the $\mathrm{CBPQT}^{4+}$ macrocycle resides over the electron-rich naphthalene. Reducing both the CBPQT macrocycle and bipyridinium unit to their radical cations $\left(\mathrm{CBPQT}^{2(+)}\right.$ and BIPY ${ }^{++}$respectively), leads to the "blue box" 30 switching to be over the bipyridinium radical cation (Figure 44). 


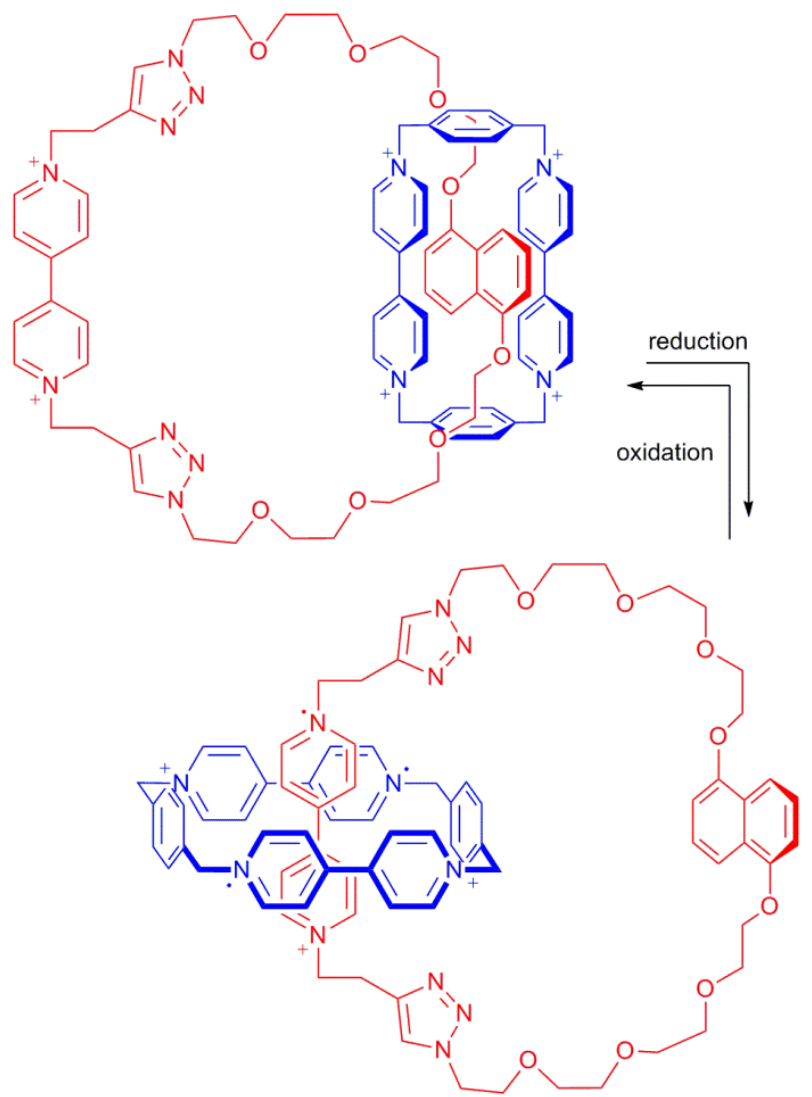

Fig. 44 Stoddart's switching [2]catenane exploiting both donor-acceptor and radical-radical interactions.

\subsection{2 $\mathrm{pH}$ induced switching}

5 Beer and co-workers constructed a phenol containing catenane by use of chloride anion templation, which was then anion exchanged to yield the hexafluorophosphate salt. Upon the addition of base, the phenol group is deprotonated to form a phenolate anion, and the rings rotate so the phenoxide may 10 hydrogen bond to the pyridinium bis-amide motif. Addition of acid reprotonates the phenolate, and so the catenane reverts to its ground state where favourable aromatic donor-acceptor interactions are maximized (Figure 45). Notably, the chloride salt of this catenane does not undergo rotation upon addition of base 15 the chloride anion is bound within the catenane cavity and therefore inhibits rotation. ${ }^{110}$

A more recent $\mathrm{pH}$ switchable [2]catenane has been reported by Furusho and Yashima. ${ }^{111}$ The catenane is prepared by use of an amidinium-carboxylate salt bridge template. The addition of acid 20 disrupts the salt bridge, inducing motion of the two rings. By addition of base, the salt bridge may be restored and the motion reversed (Figure 46). These events may be followed by changes in the colour of the fluorescence of the catenane, or due to the chirality present within the catenane, by variations in the CD 25 spectrum. This example is also an excellent illustration that molecular motion may be induced by more than one type of stimulus: the addition of a $\mathrm{Zn}^{\mathrm{II}}$ cation will also leads to salt bridge disruption, which can be reversed by addition of a cryptand to sequester the cation.
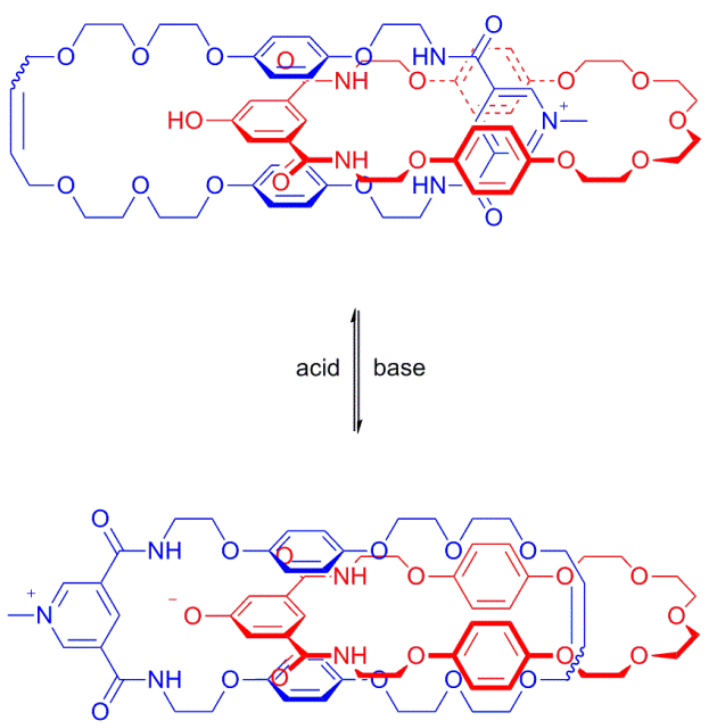

Fig. 45 A pH switchable phenol containing [2]catenane.



$\underset{\text { or [2.2.1]cryptand }}{\mathrm{PPr}_{2} \mathrm{NEt}} \|$ TFA or $\mathrm{Zn}^{2+}$

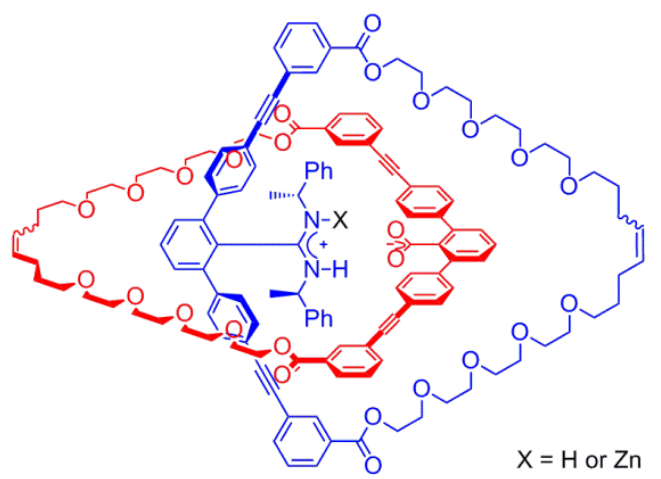

Fig. $46 \mathrm{~A}$ pH switchable amidinium-carboxylate containing [2]catenane.

\subsubsection{Cation induced switching}

35 Leigh's group have demonstrated that the $\mathrm{Pd}^{\mathrm{II}}$ templated [2]catenane depicted in Figure 13 can exhibit controllable molecular motion. ${ }^{112}$ Demetallation does not affect the coconformation of the catenane (as evidenced in the solution and solid state) because of inter-ring hydrogen bonding between the 
ligating functionality. However when exposed to $\mathrm{PdCl}_{2}(\mathrm{MeCN})_{2}$ the catenane is metallated only at the pyridine bis-ether, inducing rotation of the catenane rings (Figure 47). The lack of coordination with the pyridyl diamide group is attributed to the 5 chloride anion being of insufficient basicity to deprotonate the amides. This system has subsequently been modified to generate a catenane where a six-coordinate octahedral geometry may also be supported. A sequence of metallation and demetallation steps using $\mathrm{Pd}^{\mathrm{II}}$ and $\mathrm{Co}^{\mathrm{II}}$ cations has been shown to drive ring rotation 10 in this catenane. ${ }^{113}$

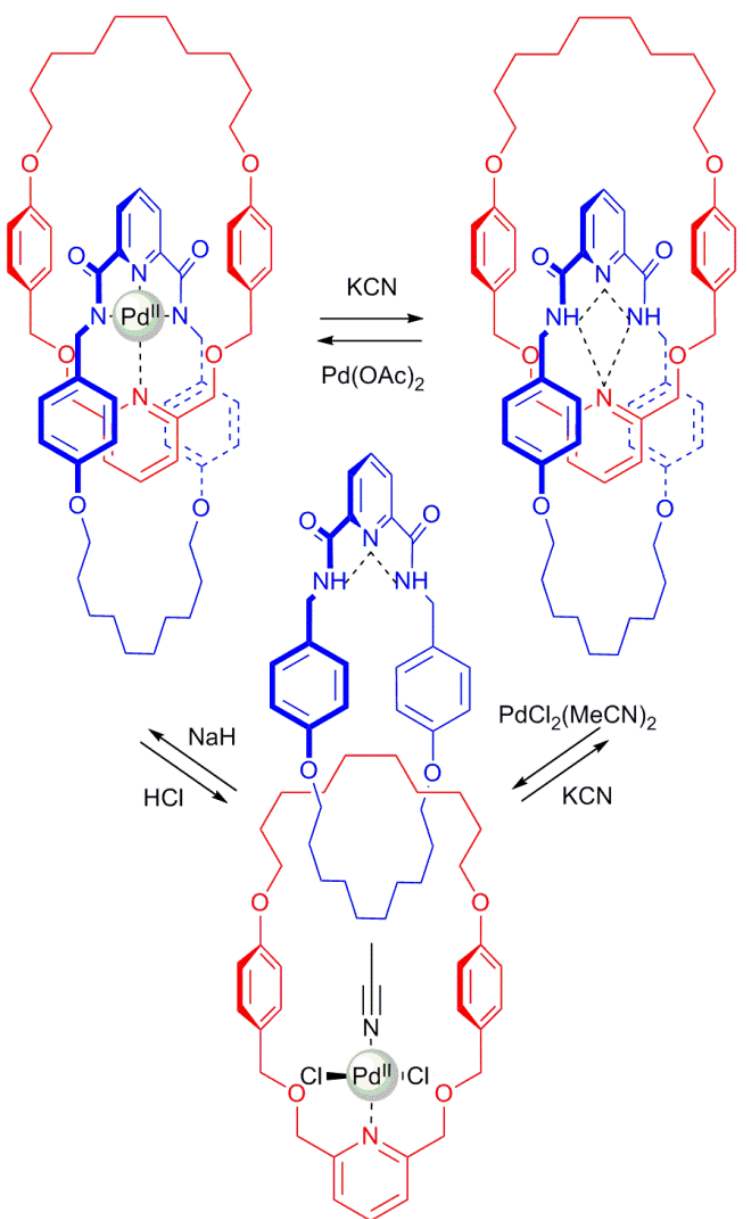

Fig. 47 Leigh’s square planar templated [2]catenane capable of undergoing controlled molecular motion.

A calixdiquinone benzyl catenane has been prepared by Beer 15 et al. After removal of the chloride anion template, the addition of $\mathrm{Ba}\left(\mathrm{ClO}_{4}\right)_{2}$ leads to molecular motion, due to the binding of the $\mathrm{Ba}^{\mathrm{II}}$ cation by the calixdiquinone, inducing displacement of the benzyl pyridinium moiety due to steric and electrostatic repulsion. These events can be reversed by precipitation of $\mathrm{Ba}^{\mathrm{II}}$ as $20 \mathrm{BaSO}_{4}$, thus leading to the description of this motion as being “spring-like" (Figure 48). ${ }^{114}$

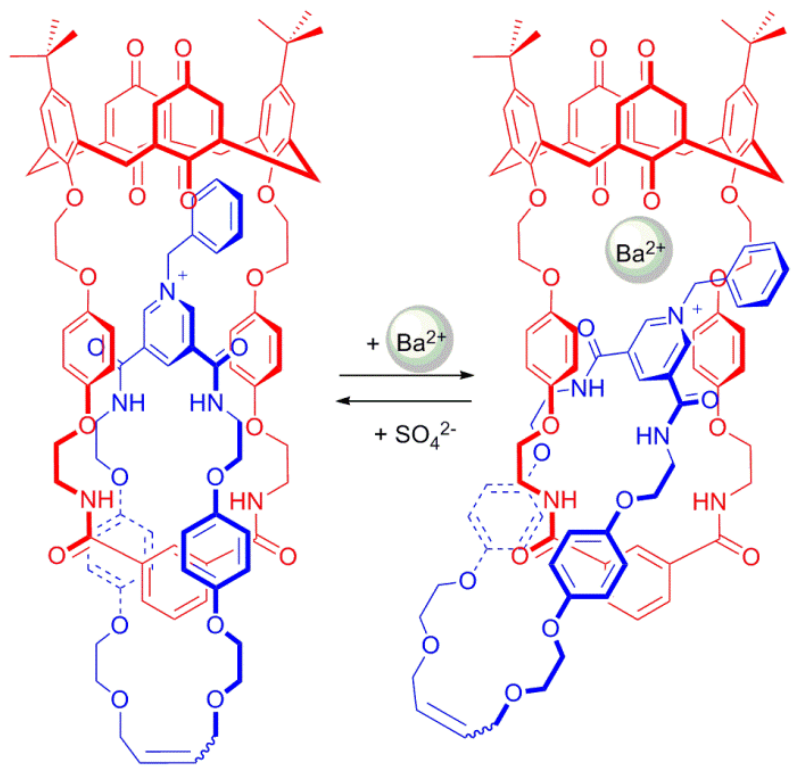

Fig. 48 Calixdiquinone [2]catenane exhibiting $\mathrm{Ba}^{\mathrm{II}}$ cation induced "spring-like" motion.

\section{4.1.4 Anion induced switching}

A neutral pyridine-containing catenane provides a rare example of co-conformational control by an anion stimulus. ${ }^{115}$ In $d_{6^{-}}$acetone, ${ }^{1} \mathrm{H}$ NMR spectroscopy provides evidence for both coconformations illustrated in Figure 49: the first where the pyridyl 30 nitrogen lone pair hydrogen bonds to the isophthalamide cleft of the other macrocycle and the other where the rings are rotated by $180^{\circ}$ with respect to one another. Upon, the addition of chloride, the catenane is locked in a single co-conformation, where the chloride is bound within the interlocked cavity by a convergent 35 array of hydrogen bonds from both amide clefts.

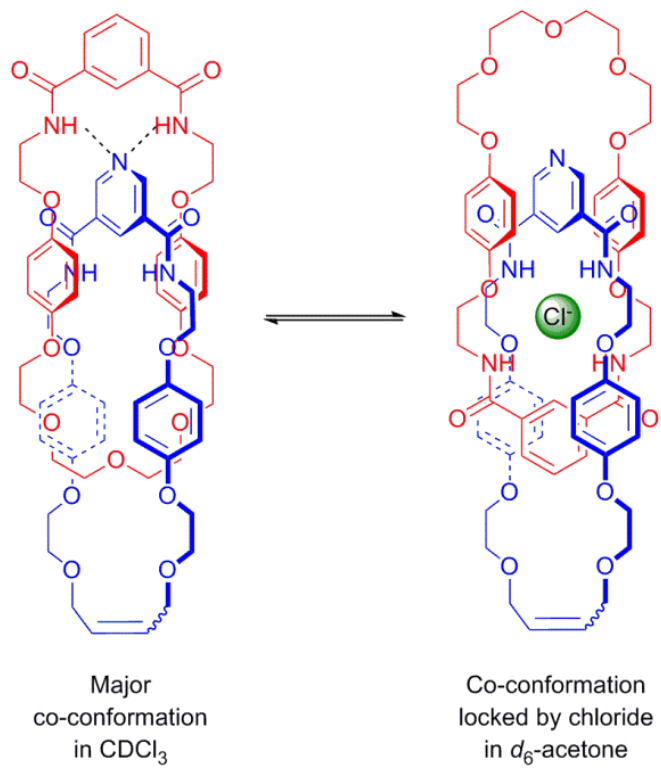

Fig. 49 A neutral [2]catenane exhibiting anion controlled coconformational behaviour. 


\section{2 “Molecular motor” catenanes}

Leigh has demonstrated it is possible to prepare catenanes demonstrating motor-like behaviour, by achieving unidirectionality of motion. ${ }^{116,} 117$ In their first example - a 5 [3]catenane - two small macrocycles precess around a much larger macrocycle containing four "stations". 116 Specific isomerizations of $\mathrm{C}=\mathrm{C}$ bonds vary the hydrogen bond accepting ability of the stations on the large macrocycle, and hence drives motion of the (hydrogen bond donating) smaller rings. After three 10 sets of isomerizations, the two small rings have swapped sites, repeating the cycle returns the catenane to its initial state (Figure 50).

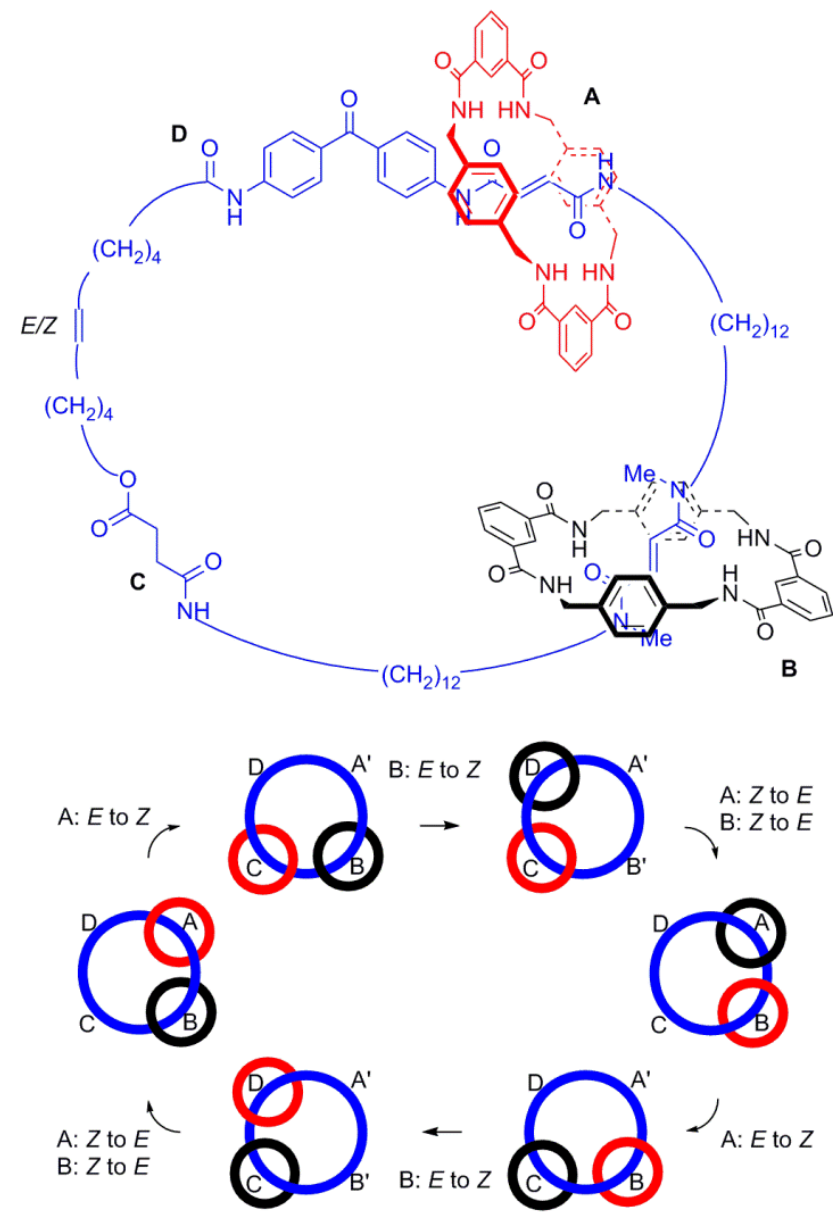

Fig. 50 Leigh's unidirectional [3]catenane.

15 In their second example, unidirectionality was demonstrated in a [2]catenane. ${ }^{117}$ Once again isomerization of an olefin is used to vary the hydrogen bond ability of a station relative to another. However, the other station is blocked on either side by different bulky substitutents. Hence, it is possible to choose which group to 20 remove to allow translation of the smaller ring to and from the olefin containing station, and hence its direction of travel around the larger macrocycle (Figure 51).

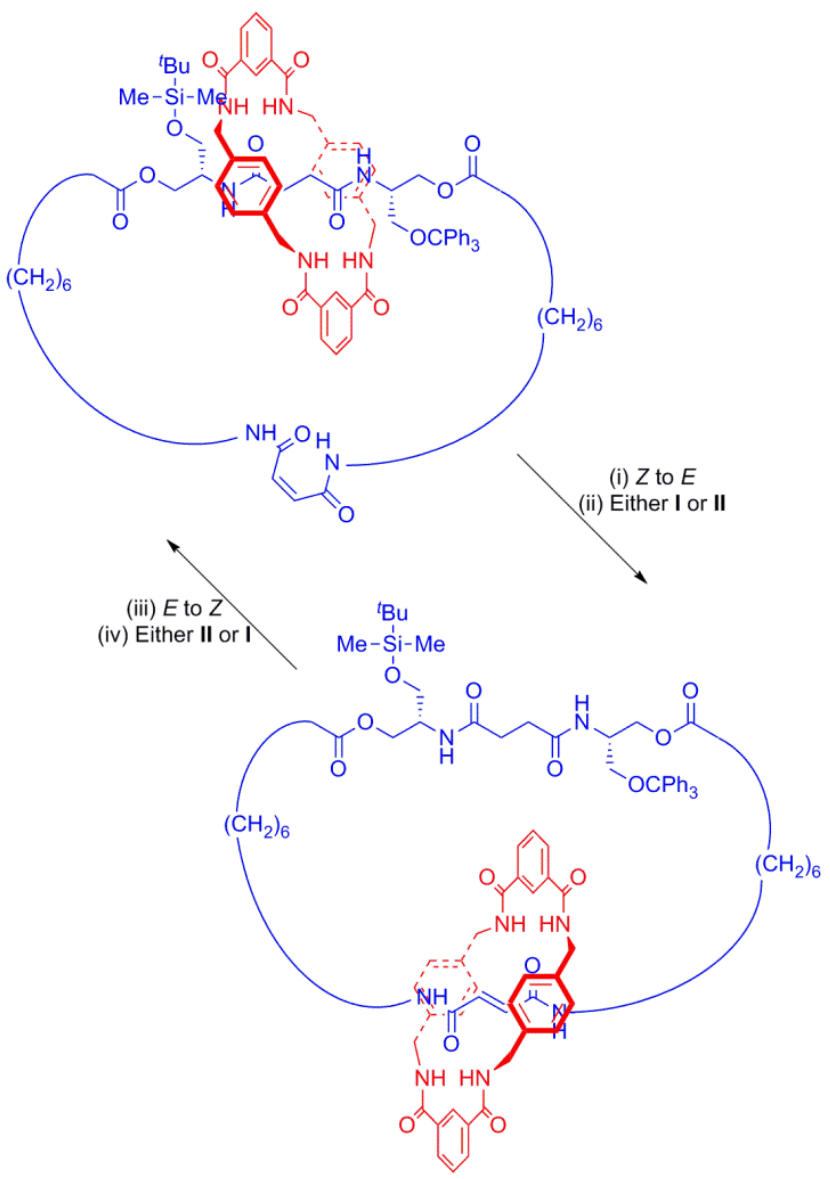

I: $-\mathrm{CPh}_{3}$ then $+\mathrm{CPh}_{3}$ \& II: $-{ }^{{ }^{\mathrm{B}} \mathrm{BuSiMe}}{ }_{3}$ then $+{ }^{{ }^{\mathrm{B}} \mathrm{BuSiMe}}{ }_{3}$

So, if (ii) = I and (iv) = II then small macrocycle precesses clockwise if (ii) = II and (iv) = I then small macrocycle precesses anti-clockwise

Fig. 51 Leigh's [2]catenane capable of selective unidirectional motion.

\section{${ }_{25} 5$. Integrating catenanes onto surfaces and into metal organic frameworks (MOFs)}

Very significant progress has been made in the solution phase construction and utilization of catenanes. For these molecules to achieve their full potential in real-world applications however,

30 may well require their incorporation into or onto some other support material or scaffold.

One such class of material are polycatenanes, polymers containing catenane structures. As mentioned in the Introduction, a recent comprehensive review has been published, ${ }^{30}$ and 35 considering much of the significant work on this area occurred before 2000, we choose not to include specific discussion of these systems here. Instead we focus on the integration of catenanes onto surfaces, and into metal organic frameworks.

\subsection{Catenanes on surfaces}

40 A structural classification of different types of surface catenane may readily be made (Figure 52). A catenane may be grafted onto a surface by one or more covalent links, the surface may form part of the actual catenane structure, or the catenane may be non-covalently physisorbed to the surface. 


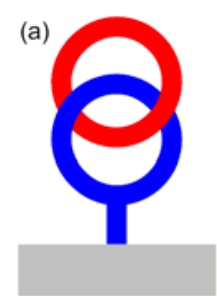

(b)

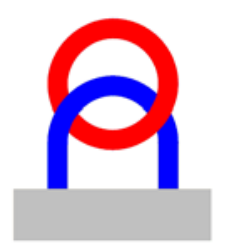

(c)

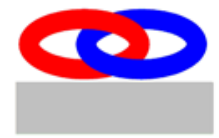

Fig. 52 Summary of types of surface-bound catenane: (a) appended to the surface by a chemisorbed linkage, (b) chemisorbed to surface, which forms part of the catenane structure and (c) physisorbed onto surface.

5 The first reported surface catenane (in 1993), by Gokel and Kaifer, incorporated a gold electrode as part of the interlocked structure. ${ }^{118}$ It was constructed by preparing a solution of the $\mathrm{CBPQT}^{4+}$ macrocycle and a hydroquinone bis-thiol appended thread, and exposing this to a gold surface to allow for catenane 10 formation by generation of Au-S bonds. The confinement of the tetracationic macrocycle to the surface was verified by electrochemistry, with the reversible reduction of the viologen groups observed by cyclic voltammetry (Figure 53).
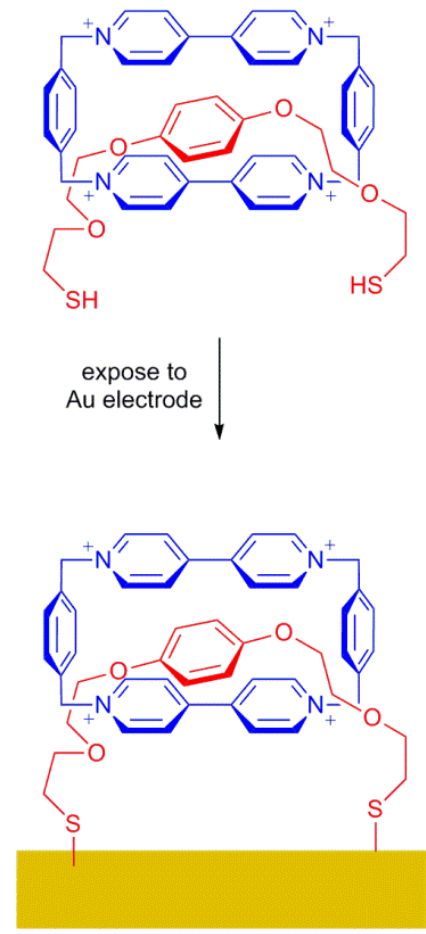

Fig. 53 Gokel and Kaifer’s preparation of a surface catenane.

Sauvage and co-workers have investigated the attachment of his $\mathrm{Cu}^{\mathrm{I}}$ template catenanes onto surfaces. ${ }^{119,} 120$ The successful fabrication of monolayers onto gold has been achieved by two methods: (a) surface capture of thiol-functionalized pseudo20 rotaxanes and $(b)$ in situ cleavage and chemisorption of solution phase disulfide catenanes (Figure 54). However, monolayers consisting of catenanes analogous to the solution-phase electrochemically triggered catenane presented above appeared not to undergo switchable molecular motion on the surface.

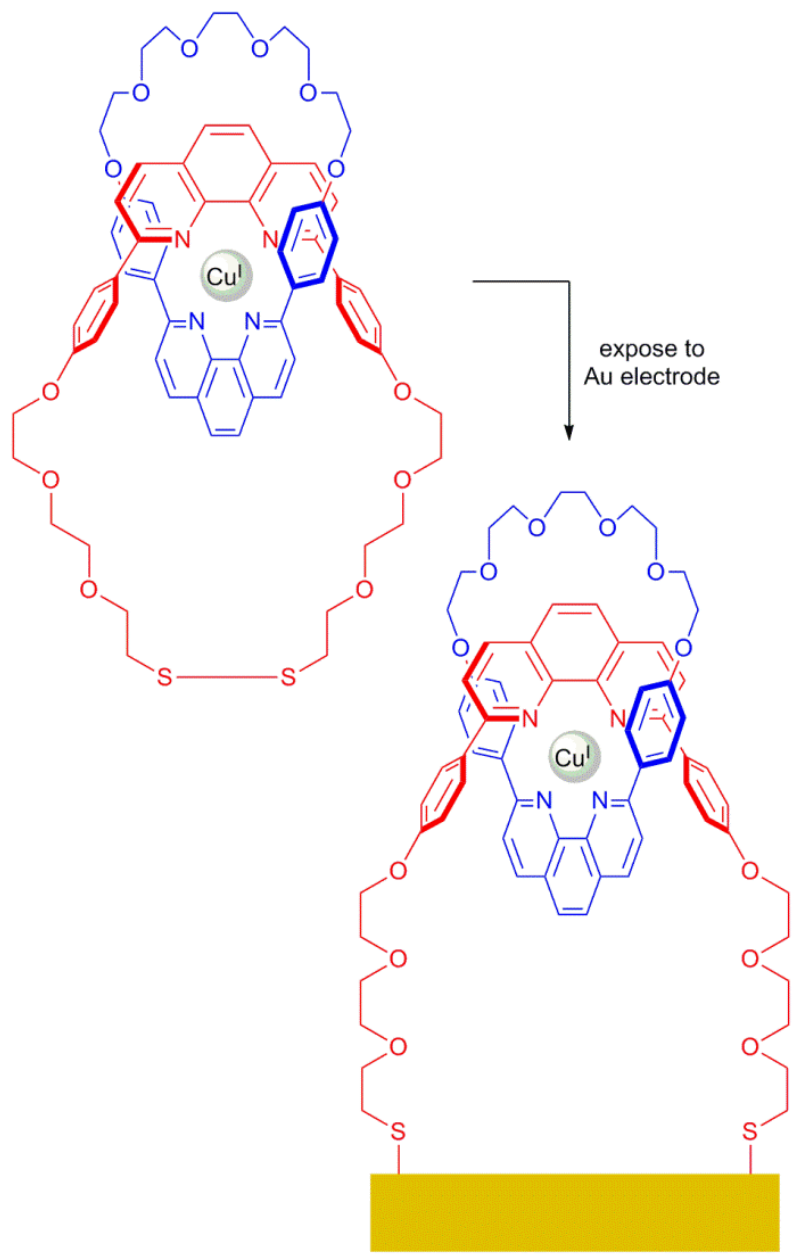

Fig. 54 Sauvage's preparation of a surface catenane using a pre-formed solution phase disulfide catenane.

Beer and Davis have constructed a surface confined analogue of the solution phase ferrocene-appended [2]catenane (Figure 30 55). By use of high resolution X-ray photoelectron spectroscopy (XPS) it was possible to probe the elemental composition of the catenane at different distances from the source. However, it was found that it was not possible to investigate the electrochemical recognition properties of the surface catenane, due to an inability 35 to remove the chloride anion template. This was attributed to the anion being bound very strongly by the surface preorganized catenane. $^{66}$

An example of a catenane grafted onto a surface by covalent links has been reported by Leigh and co-workers. ${ }^{121}$ XPS 40 indicates that there is an intermediate stage of monolayer formation where only one of the thiol groups per catenane is bonded to the surface (Figure 56). More recently, Stoddart has attached the switchable TTF/naphthalene catenane described above onto the surface of noble metal nanoparticles by means of 45 a tether, and demonstrated that the electrochemical or chemical switching of the catenane was still possible. ${ }^{122}$ 


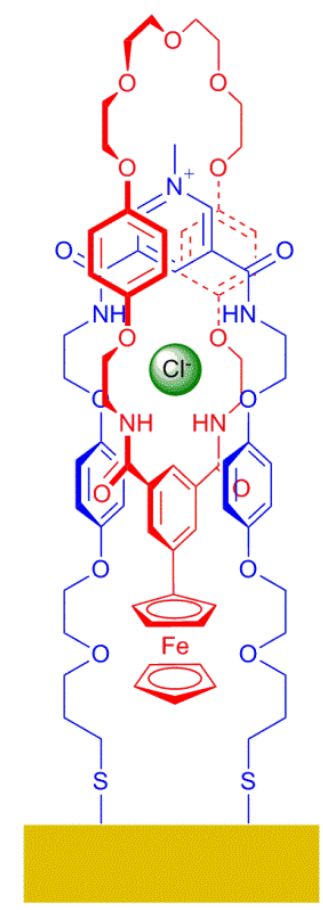

Fig. 55 Beer and Davis’ chloride anion templated ferrocene appended catenane.

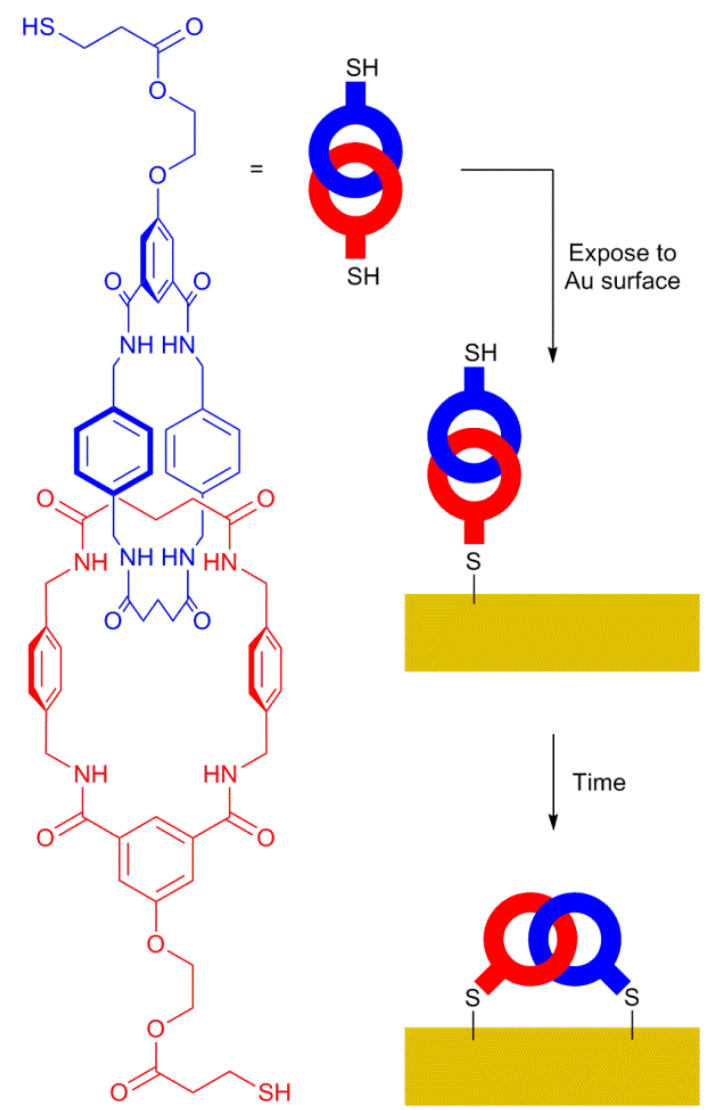

$5 \quad$ Fig. $\mathbf{5 6}$ Leigh's catenane chemisorbed to a surface by an appended linkage.

Arguably the simplest fabrication of a catenane onto a surface is via physisorption. For example, Sauvage's original catenane has been deposited onto a silver surface by vacuum
10 sublimation. ${ }^{123}$ It was observed that the metal-free catenane selfassembles as dimeric chains, but upon the addition of copper atoms, this structure is disrupted, resulting in isolated, unarranged catenanes on the surface, indicating ring rotation. XPS of the nitrogen atom core energy levels provides supporting evidence 15 that $\mathrm{Cu}$ is being coordinated by the catenane.

Stoddart and Heath have prepared a solid-state switching device by once again using the switchable TTF/naphthalene catenane. ${ }^{124}$ A phospholipid-catenane monolayer was prepared using a Langmuir trough, and then sandwiched between ${ }_{20}$ polysilicon and Ti/Al electrodes. The switch exhibited hysteric (bistable) current/voltage characteristics, could be opened with an applied voltage of $+2 \mathrm{~V}$ and closed at $-2 \mathrm{~V}$, and read at $\approx 0.1 \mathrm{~V}$, and was "recyclable" under ambient conditions. The authors proposed a mechanochemical mechanism for the action of the 25 switch.

Very recently, B. D. Smith and co-workers reported upon polystyrene nanoparticles stained with squaraine catenane endoperoxide (Figure 57). ${ }^{125}$ The catenane may undergo a thermally-activated cycloreversion that releases singlet oxygen, 30 which then triggers chemiluminescence from the encapsulated squaraine dye. Impressively, the catenane was used to obtain in vivo images in mice.

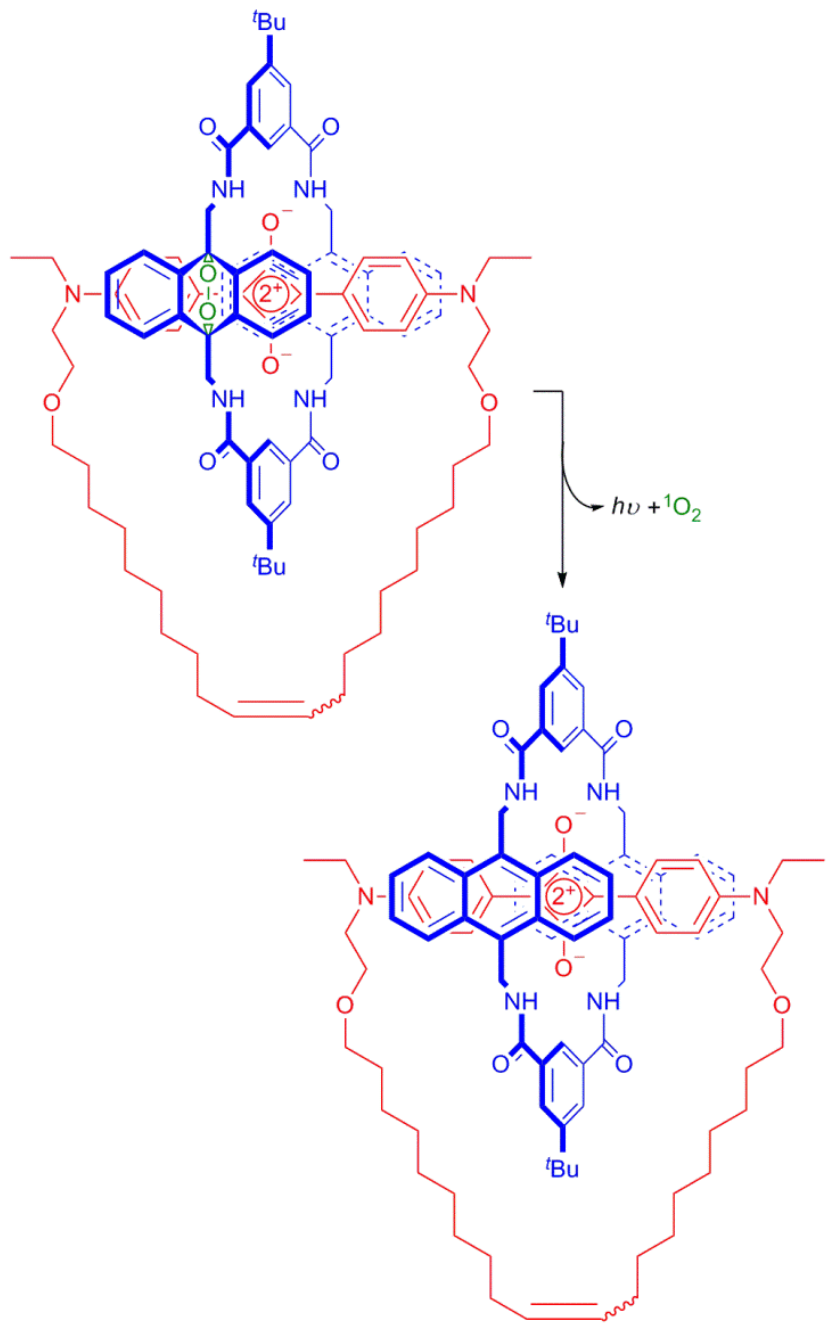

Fig. 57 Structure and thermal cycloreversion of B. D. Smith’s squaraine catenane endoperoxide used to stain polystyrene nanoparticles. 


\subsection{Catenanes in Metal Organic Frameworks (MOFs)}

Metal organic frameworks (MOFs) are crystalline compounds made of metal cations coordinated to rigid organic ligands to form an extended structure in one, two or three dimensions. 5 Typically these structures possess networks of pores - reminiscent of zeolites - which can be used for storage, sensing and catalysis. $^{126}$

Stoddart, Yaghi and co-workers incorporated aromatic donoracceptor charge-transfer [2]catenanes as parts of rigid organic 10 ligands in both 2D and 3D MOFs in 2010. ${ }^{127,} 128$ The two MOFs were formed by heating a catenated strut (displayed in Figure 58a) with hydrated $\mathrm{Cu}\left(\mathrm{NO}_{3}\right)_{2}$ in an aqueous solvent mix. Single crystals suitable for X-ray diffraction were obtained. In both MOFs each $\mathrm{Cu}^{\mathrm{I}}$ cation is bound to two carboxylate groups from 15 two catenane molecules and to one acetylenic bond from a third catenane. In the case of the 2D MOF the $\mathrm{Cu}^{\mathrm{I}}$ cations and the backbones of the catenane molecules form the $2 \mathrm{D}$ network with the interlocking rings of the catenane alternating up and down throughout the layer (Figure 58b). ${ }^{127}$ In the case of the 3D MOF,

20 it was noted that the length of the strut provides vast openness to accommodate the catenanes within the framework, and that the "backbone" of the MOF is itself catenated, attributed to the slenderness of the strut. ${ }^{128}$ Very recently, new MOFs have been generated using a new strut where the acetylenic bond has been 25 removed, hence eliminating $\eta^{2}$ binding to the $\mathrm{C}-\mathrm{C}$ triple bond. In these MOFs, separate alternating 2D layers are linked by $\pi-\pi$ stacking interactions, with $R R$ and $S S$ enantiomers of the catenane alternating with each other from layer to layer. ${ }^{129}$

(a)



(b)

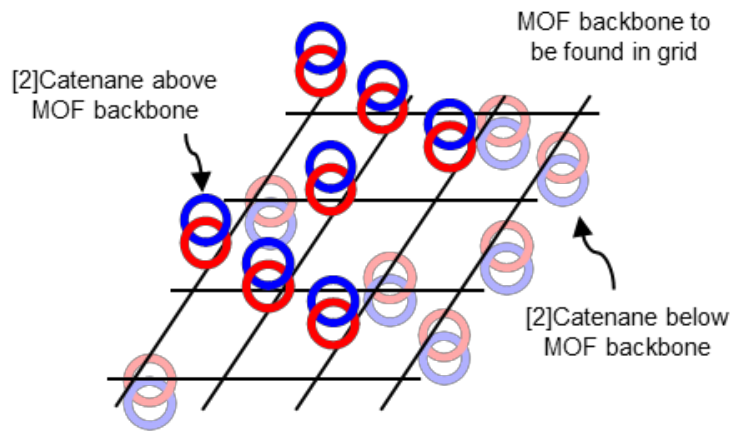

30 Fig. 58 Stoddart and Yaghi's first 2D MOF containing catenated struts: (a) structure of [2]catenane unit and (b) schematic representation of 2D layer of MOF.

At present work has been limited to the synthesis and structural determination of MOFs containing static catenanes. In
35 the future, we anticipate the integration of switchable catenanes into MOFs, particularly in light of the recent success of Loeb and co-workers in incorporating dynamic rotaxanes into MOFs (sometimes referred to as "MORFs"). ${ }^{130}$

\section{Conclusions}

${ }_{40}$ Even in this non-comprehensive and hence selective review, it can clearly be seen that a variety of useful template synthetic methodologies are now available to prepare synthetic catenanes. Cations, anions, aromatic donor-acceptor interactions, hydrogen and halogen bonding have all been used to aid the assembly of 45 such interlocked molecules. In addition, the application of dynamic combinatorial chemistry has revealed a genuinely exciting alternative pathway to discovering new catenane structures.

As a consequence of these (continuing) synthetic advances, 50 catenanes are increasingly being incorporated into a range of functional molecular devices, for example as molecular machines driven by a range of physical and chemical stimuli, as well as molecular hosts and sensors. Looking forward, the fabrication of catenanes onto surfaces and into extended structures, to allow for 55 greater opportunity to utilize these molecules in real-world nanotechnological scenarios, remains an attractive research theme.

It is now some thirty years since Jean-Pierre Sauvage's seminal communication of the first synthesis of a metallo60 catenane, we predict that further novel templation methodologies will continue to be reported, and that ever more intricate and sophisticated higher-order catenane species will be prepared. The road ahead is rich with opportunities for chemists to make new discoveries about, and to further exploit these fascinating 65 molecules.

We wish to thank the many group members and collaborators for all their efforts that contributed towards the research on catenanes that has been carried out in the laboratories of P. D. B. in Oxford. P. D. B. acknowledges funding from the EPSRC, the 70 European Research Council (Advanced Grant), the European Union for Marie Curie Fellowships, the Clarendon Fund and the Royal Commission for the Exhibition of 1851. In addition, N. H. E. wishes to thank the EPSRC for the funding of his doctoral studentship at Oxford, and Lancaster University for their 75 current on-going financial support.

\section{Notes and references}

${ }^{a}$ Department of Chemistry, Lancaster University, Lancaster. LA1 4YB. UK. Tel: +44 (0)1524 594538; E-mail: n.h.evans@lancaster.ac.uk.

${ }^{b}$ Inorganic Chemistry Laboratory, Department of Chemistry, Oxford

80 University, South Parks Road, Oxford. OX1 3QR. UK. Tel: +44 (0)1865 285142; E-mail: paul.beer@chem.ox.ac.uk.

$\dagger$ This review is dedicated to Prof. Jean-Pierre Sauvage on the occasion of his $70^{\text {th }}$ birthday.

$\ddagger$ An [ $n$ ]catenane consists of $n$ interlocked rings, e.g. a [2]catenane 85 consists of two rings, a [3]catenane of three, and so on.

$\S$ Strictly this is not true, as Grubbs' metathesis catalysts allow for reversible $\mathrm{C}=\mathrm{C}$ bond formation, as discussed in Section 3.4.2.

1. R. S. Forgan, J.-P. Sauvage and J. F. Stoddart, Chem Rev, 2011, 111, 90 5434-5464. 
2. C. O. Dietrich-Buchecker and J.-P. Sauvage, Angew Chem Int Edit Engl, 1989, 28, 189-192.

3. P. R. Ashton, O. A. Matthews, S. Menzer, F. M. Raymo, N. Spencer, J. F. Stoddart and D. J. Williams, Liebigs Ann-Recl, 1997, 2485-2494.

4. J. Guo, P. C. Mayers, G. A. Breault and C. A. Hunter, Nat Chem, 2010, 2, 218-222.

5. P. E. Barran, H. L. Cole, S. M. Goldup, D. A. Leigh, P. R. McGonigal, M. D. Symes, J. Y. Wu and M. Zengerle, Angew

$10 \quad$ Chem Int Edit, 2011, 50, 12280-12284.

6. N. Ponnuswamy, F. B. L. Cougnon, J. M. Clough, G. D. Pantoş and J. K. M. Sanders, Science, 2012, 338, 783-785.

7. J. F. Ayme, J. E. Beves, D. A. Leigh, R. T. McBurney, K. Rissanen and D. Schultz, Nat Chem, 2012, 4, 15-20.

15 8. J. F. Ayme, J. E. Beves, D. A. Leigh, R. T. McBurney, K. Rissanen and D. Schultz, J Am Chem Soc, 2012, 134, 9488-9497.

9. K. S. Chichak, S. J. Cantrill, A. R. Pease, S.-H. Chiu, G. W. V. Cave, J. L. Atwood and J. F. Stoddart, Science, 2004, 304, 13081312.

20 10. S. J. Cantrill, K. S. Chichak, A. J. Peters and J. F. Stoddart, Accounts Chem Res, 2005, 38, 1-9.

11. J. F. Nierengarten, C. O. Dietrich-Buchecker and J.-P. Sauvage, J Am Chem Soc, 1994, 116, 375-376.

12. C. D. Pentecost, K. S. Chichak, A. J. Peters, G. W. V. Cave, S. J. 25 Cantrill and J. F. Stoddart, Angew Chem Int Edit, 2007, 46, 218-222.

13. J. E. Beves, C. J. Campbell, D. A. Leigh and R. G. Pritchard, Angew Chem Int Edit, 2013, 52, 6464-6467.

14. M. Fujita, N. Fujita, K. Ogura and K. Yamaguchi, Nature, 1999, 400, $30 \quad 52-55$.

15. Y. T. Li, K. M. Mullen, T. D. W. Claridge, P. J. Costa, V. Felix and P. D. Beer, Chem Commun, 2009, 7134-7136.

16. T. Hasell, X. F. Wu, J. T. A. Jones, J. Bacsa, A. Steiner, T. Mitra, A. Trewin, D. J. Adams and A. I. Cooper, Nat Chem, 2010, 2,

17. S. Freye, J. Hey, A. Torras-Galán, D. Stalke, R. Herbst-Irmer, M. John and G. H. Clever, Angew Chem Int Edit, 2012, 51, 21912194.

18. E. R. Kay, D. A. Leigh and F. Zerbetto, Angew Chem Int Edit, 2007, $40 \quad$ 46, 72-191.

19. M. J. Chmielewski, J. J. Davis and P. D. Beer, Org Biomol Chem, 2009, 7, 415-424.

20. B. Hudson and J. Vinograd, Nature, 1967, 216, 647-652.

21. D. A. Clayton and J. Vinograd, Nature, 1967, 216, 652-657.

45 22. E. Wasserman, J Am Chem Soc, 1960, 82, 4433-4434.

23. G. Schill and A. Lüttringhaus, Angew Chem Int Edit, 1964, 3, 546547.

24. G. Schill, Catenanes, Rotaxanes and Knots, Academic Press, New York, 1971.

50 25. C. O. Dietrich-Buchecker, J.-P. Sauvage and J.-P. Kintzinger, Tetrahedron Lett, 1983, 24, 5095-5098.

26. J.-P. Sauvage, Acc Chem Res, 1990, 23, 319-327.

27. D. Philp and J. F. Stoddart, Angew Chem Int Edit, 1996, 35, 11551196.

55 28. D. G. Hamilton, J. K. M. Sanders, J. E. Davies, W. Clegg and S. J. Teat, Chem Commun, 1997, 897-898.
29. R. Jäger and F. Vögtle, Angew Chem Int Edit Engl, 1997, 36, 930944.

30. Z. B. Niu and H. W. Gibson, Chem Rev, 2009, 109, 6024-6046.

60 31. X. G. Liang, H. Kuhn and M. D. Frank-Kamenetskii, Biophys J, 2006, 90, 2877-2889.

32. R. Kumar, A. El-Sagheer, J. Tumpane, P. Lincoln, L. M. Wilhelmsson and T. Brown, J Am Chem Soc, 2007, 129, 68596864.

65 33. D. R. Han, S. Pal, Y. Liu and H. Yan, Nat Nanotechnol, 2010, 5, $712-$ 717.

34. T. L. Schmidt and A. Heckel, Nano Lett, 2011, 11, 1739-1742.

35. J. D. Megiatto and D. I. Schuster, Org Lett, 2011, 13, 1808-1811.

36. M. Cesario, C. O. Dietrich-Buchecker, J. Guilhem, C. Pascard and J.-

70 P. Sauvage, J Chem Soc Chem Comm, 1985, 244-247.

37. J.-P. Sauvage and J. Weiss, J Am Chem Soc, 1985, 107, 6108-6110.

38. C. O. Dietrich-Buchecker, A. Khemiss and J.-P. Sauvage, J Chem Soc Chem Comm, 1986, 1376-1378.

39. D. K. Mitchell and J.-P. Sauvage, Angew Chem Int Ed Engl, 1988, 75 27, 930-931.

40. B. Mohr, M. Weck, J.-P. Sauvage and R. H. Grubbs, Angew Chem Int Ed Engl, 1997, 36, 1308-1310.

41. M. Weck, B. Mohr, J.-P. Sauvage and R. H. Grubbs, J Org Chem, 1999, 64, 5463-5471.

80 42. P. R. Ashton, T. T. Goodnow, A. E. Kaifer, M. V. Reddington, A. M. Z. Slawin, N. Spencer, J. F. Stoddart, C. Vicent and D. J. Williams, Angew Chem Int Edit Engl, 1989, 28, 1396-1399.

43. O. Š. Miljanić, W. R. Dichtel, S. I. Khan, S. Mortezaei, J. R. Heath and J. F. Stoddart, J Am Chem Soc, 2007, 129, 8236-8246.

85 44. W. R. Dichtel, O. Š. Miljanić, W. Y. Zhang, J. M. Spruell, K. Patel, I. Aprahamian, J. R. Heath and J. F. Stoddart, Acc Chem Res, 2008, 41, 1750-1761.

45. C. A. Hunter, J Am Chem Soc, 1992, 114, 5303-5311.

46. F. Vögtle, S. Meier and R. Hoss, Angew Chem Int Edit Engl, 1992,

$90 \quad 31,1619-1622$.

47. A. G. Johnston, D. A. Leigh, L. Nezhat, J. P. Smart and M. D. Deegan, Angew Chem Int Edit Engl, 1995, 34, 1212-1216.

48. A. G. Johnston, D. A. Leigh, R. J. Pritchard and M. D. Deegan, Angew Chem Int Edit Engl, 1995, 34, 1209-1212.

95 49. J.-P. Sauvage and M. Ward, Inorg Chem, 1991, 30, 3869-3874.

50. D. A. Leigh, P. J. Lusby, S. J. Teat, A. J. Wilson and J. K. Y. Wong, Angew Chem Int Edit, 2001, 40, 1538-1543.

51. D. A. Leigh, P. J. Lusby, R. T. McBurney, A. Morelli, A. M. Z. Slawin, A. R. Thomson and D. B. Walker, J Am Chem Soc,

$100 \quad 2009,131,3762-3771$.

52. J. F. Ayme, J. Lux, J.-P. Sauvage and A. Sour, Chem-Eur J, 2012, 18, 5565-5573.

53. A.-M. L. Fuller, D. A. Leigh, P. J. Lusby, A. M. Z. Slawin and D. B. Walker, J Am Chem Soc, 2005, 127, 12612-12619.

105 54. C. Hamann, J.-M. Kern and J.-P. Sauvage, Inorg Chem, 2003, 42, 1877-1883.

55. S. M. Goldup, D. A. Leigh, P. J. Lusby, R. T. McBurney and A. M. Z. Slawin, Angew Chem Int Edit, 2008, 47, 6999-7003.

56. S.-T. Tung, C.-C. Lai, Y.-H. Liu, S.-M. Peng and S.-H. Chiu, Angew $110 \quad$ Chem Int Edit, 2013, 52, 13269-13272.

57. J. D. Crowley, S. M. Goldup, A.-L. Lee, D. A. Leigh and R. T. McBurney, Chem Soc Rev, 2009, 38, 1530-1541. 
58. Y. Sato, R. Yamasaki and S. Saito, Angew Chem Int Edit, 2009, 48, 504-507.

59. S. M. Goldup, D. A. Leigh, T. Long, P. R. McGonigal, M. D. Symes and J. Wu, J Am Chem Soc, 2009, 131, 15924-15929.

5 60. M. J. Langton, J. D. Matichak, A. L. Thompson and H. L. Anderson, Chem Sci, 2011, 2, 1897-1901.

61. A. Andrievsky, F. Ahuis, J. L. Sessler, F. Vögtle, D. Gudat and M. Moini, J Am Chem Soc, 1998, 120, 9712-9713.

62. M. R. Sambrook, P. D. Beer, J. A. Wisner, R. L. Paul and A. R. 10 Cowley, J Am Chem Soc, 2004, 126, 15364-15365.

63. K. Kavallieratos, S. R. deGala, D. J. Austin and R. H. Crabtree, J Am Chem Soc, 1997, 119, 2325-2326.

64. L. M. Hancock, L. C. Gilday, N. L. Kilah, C. J. Serpell and P. D. Beer, Chem Commun, 2011, 47, 1725-1727.

15 65. N. G. White and P. D. Beer, Chem Commun, 2012, 48, 8499-8501.

66. N. H. Evans, H. Rahman, A. V. Leontiev, N. D. Greenham, G. A. Orlowski, Q. Zeng, R. M. J. Jacobs, C. J. Serpell, N. L. Kilah, J. J. Davis and P. D. Beer, Chem Sci, 2012, 3, 1080-1089.

67. N. H. Evans, C. J. Serpell and P. D. Beer, Angew Chem Int Edit, $20 \quad$ 2011, 50, 2507-2510.

68. K.-Y. Ng, A. R. Cowley and P. D. Beer, Chem Commun, 2006, 36763678.

69. N. H. Evans, E. S. H. Allinson, M. D. Lankshear, K.-Y. Ng, A. R. Cowley, C. J. Serpell, S. M. Santos, P. J. Costa, V. Félix and

25 P. D. Beer, Rsc Adv, 2011, 1, 995-1003.

70. B. Q. Huang, S. M. Santos, V. Felix and P. D. Beer, Chem Commun, 2008, 4610-4612.

71. M. K. Chae, J. M. Suk and K. S. Jeong, Tetrahedron Lett, 2010, 51, 4240-4242.

30 72. Y. J. Zhao, Y. L. Li, Y. J. Li, H. Y. Zheng, X. D. Yin and H. B. Liu, Chem Commun, 2010, 46, 5698-5700.

73. J. J. Lee, J. M. Baumes, R. D. Connell, A. G. Oliver and B. D. Smith, Chem Commun, 2011, 47, 7188-7190.

74. G. Cavallo, P. Metrangolo, T. Pilati, G. Resnati, M. Sansotera and G.

35 Terraneo, Chem Soc Rev, 2010, 39, 3772-3783.

75. T. M. Beale, M. G. Chudzinski, M. G. Sarwar and M. S. Taylor, Chem Soc Rev, 2013, 42, 1667-1680.

76. A. Caballero, F. Zapata, N. G. White, P. J. Costa, V. Félix and P. D. Beer, Angew Chem Int Edit, 2012, 51, 1876-1880.

40 77. L. C. Gilday, T. Lang, A. Caballero, P. J. Costa, V. Félix and P. D. Beer, Angew Chem Int Edit, 2013, 52, 4356-4360.

78. J. C. Barnes, A. C. Fahrenbach, D. Cao, S. M. Dyar, M. Frasconi, M. A. Giesener, D. Benítez, E. Tkatchouk, O. Chernyashevskyy, W. H. Shin, H. Li, S. Sampath, C. L. Stern, A. A. Sarjeant, K.

45 J. Hartlieb, Z. C. Liu, R. Carmieli, Y. Y. Botros, J. W. Choi, A. M. Z. Slawin, J. B. Ketterson, M. R. Wasielewski, W. A. Goddard and J. F. Stoddart, Science, 2013, 339, 429-433.

79. M. Fujita, F. Ibukuro, H. Hagihara and K. Ogura, Nature, 1994, 367, 720-723.

50 80. M. Fujita and K. Ogura, Coord Chem Rev, 1996, 148, 249-264.

81. M. Fujita, Acc Chem Res, 1999, 32, 53-61.

82. M. Chas, E. Pia, R. Toba, C. Peinador and J. M. Quintela, Inorg Chem, 2006, 45, 6117-6119.

83. M. Chas, V. Blanco, C. Peinador and J. M. Quintela, Org Lett, 2007, $55 \quad 9,675-678$.
84. V. Blanco, M. Chas, D. Abella, C. Peinador and J. M. Quintela, J Am Chem Soc, 2007, 129, 13978-13986.

85. P. D. Beer, N. Berry, M. G. B. Drew, O. D. Fox, M. E. Padilla-Tosta and S. Patell, Chem Commun, 2001, 199-200.

60 86. W. W. H. Wong, J. Cookson, E. A. L. Evans, E. J. L. McInnes, J. Wolowska, J. P. Maher, P. Bishop and P. D. Beer, Chem Commun, 2005, 2214-2216.

87. B. A. Blight, J. A. Wisner and M. C. Jennings, Angew Chem Int Edit, 2007, 46, 2835-2838.

65 88. W. Wang, L. Q. Wang, B. J. Palmer, G. J. Exarhos and A. D. Q. Li, J Am Chem Soc, 2006, 128, 11150-11159.

89. E. N. Guidry, S. J. Cantrill, J. F. Stoddart and R. H. Grubbs, Org Lett, 2005, 7, 2129-2132.

90. M. Hutin, C. A. Schalley, G. Bernardinelli and J. R. Nitschke, Chem$70 \quad$ Eur J, 2006, 12, 4069-4076.

91. J. R. Price, J. K. Clegg, R. R. Fenton, L. F. Lindoy, J. C. McMurtrie, G. V. Meehan, A. Parkin, D. Perkins and P. Turner, Aust $J$ Chem, 2009, 62, 1014-1019.

92. O. Š. Miljanić and J. F. Stoddart, P Natl Acad Sci USA, 2007, 104, 75 12966-12970.

93. K. Patel, O. Š. Miljanić and J. F. Stoddart, Chem Commun, 2008, 1853-1855.

94. R. T. S. Lam, A. Belenguer, S. L. Roberts, C. Naumann, T. Jarrosson, S. Otto and J. K. M. Sanders, Science, 2005, 308, 667-669.

80 95. M.-K. Chung, P. S. White, S. J. Lee and M. R. Gagné, Angew Chem Int Edit, 2009, 48, 8683-8686.

96. M.-K. Chung, P. S. White, S. J. Lee, M. L. Waters and M. R. Gagné, J Am Chem Soc, 2012, 134, 11415-11429.

97. M.-K. Chung, S. J. Lee, M. L. Waters and M. R. Gagné, J Am Chem 85 Soc, 2012, 134, 11430-11443.

98. H. Y. Au-Yeung, G. D. Pantoş and J. K. M. Sanders, P Natl Acad Sci USA, 2009, 106, 10466-10470.

99. H. Y. Au-Yeung, G. D. Pantoş and J. K. M. Sanders, J Am Chem Soc, 2009, 131, 16030-16032.

90 100.H. Y. Au-Yeung, G. D. Pantoş and J. K. M. Sanders, Angew Chem Int Edit, 2010, 49, 5331-5334.

101.H. Y. Au-Yeung, G. D. Pantoş and J. K. M. Sanders, J Org Chem, 2011, 76, 1257-1268.

102.F. B. L. Cougnon, H. Y. Au-Yeung, G. D. Pantoş and J. K. M. Sanders, J Am Chem Soc, 2011, 133, 3198-3207.

103.F. B. L. Cougnon, N. A. Jenkins, G. D. Pantoş and J. K. M. Sanders, Angew Chem Int Edit, 2012, 51, 1443-1447.

104.F. B. L. Cougnon, N. Ponnuswamy, N. A. Jenkins, G. D. Pantoş and J. K. M. Sanders, J Am Chem Soc, 2012, 134, 19129-19135.

100 105.A. Livoreil, C. O. Dietrich-Buchecker and J.-P. Sauvage, J Am Chem Soc, 1994, 116, 9399-9400.

106.D. J. Cárdenas, A. Livoreil and J.-P. Sauvage, J Am Chem Soc, 1996, 118, 11980-11981.

107.B. Korybut-Daszkiewicz, A. Więckowska, R. Bilewicz, S. Domagała $105 \quad$ and K. Woźniak, Angew Chem Int Edit, 2004, 43, 1668-1672.

108.M. Asakawa, P. R. Ashton, V. Balzani, A. Credi, C. Hamers, G. Mattersteig, M. Montalti, A. N. Shipway, N. Spencer, J. F. Stoddart, M. S. Tolley, M. Venturi, A. J. P. White and D. J. Williams, Angew Chem Int Edit, 1998, 37, 333-337.

110 109.Z. X. Zhu, A. C. Fahrenbach, H. Li, J. C. Barnes, Z. C. Liu, S. M. Dyar, H. C. Zhang, J. Y. Lei, R. Carmieli, A. A. Sarjeant, C. 
L. Stern, M. R. Wasielewski and J. F. Stoddart, J Am Chem Soc, 2012, 134, 11709-11720.

110.K.-Y. Ng, V. Félix, S. M. Santos, N. H. Rees and P. D. Beer, Chem Commun, 2008, 1281-1283.

5 111.Y. Nakatani, Y. Furusho and E. Yashima, Angew Chem Int Edit, 2010, 49, 5463-5467.

112.D. A. Leigh, P. J. Lusby, A. M. Z. Slawin and D. B. Walker, Chem Commun, 2005, 4919-4921.

113.D. A. Leigh, P. J. Lusby, A. M. Z. Slawin and D. B. Walker, Chem

$10 \quad$ Commun, 2012, 48, 5826-5828.

114.A. V. Leontiev, C. J. Serpell, N. G. White and P. D. Beer, Chem Sci, 2011, 2, 922-927.

115.N. H. Evans, C. J. Serpell and P. D. Beer, Chem-Eur J, 2011, 17, 7734-7738.

15 116.D. A. Leigh, J. K. Y. Wong, F. Dehez and F. Zerbetto, Nature, 2003, 424, 174-179.

117.J. V. Hernández, E. R. Kay and D. A. Leigh, Science, 2004, 306, 1532-1537.

118.T. B. Lu, L. Zhang, G. W. Gokel and A. E. Kaifer, J Am Chem Soc,

$20 \quad$ 1993, 115, 2542-2543.

119.L. Raehm, C. Hamann, J.-M. Kern and J.-P. Sauvage, Org Lett, 2000, 2, 1991-1994.

120.L. Raehm, J.-M. Kern, J.-P. Sauvage, C. Hamann, S. Palacin and J.P. Bourgoin, Chem-Eur J, 2002, 8, 2153-2162.

25 121.C. De Nadaï, C. M. Whelan, C. Perollier, G. Clarkson, D. A. Leigh, R. Caudano and P. Rudolf, Surf Sci, 2000, 454, 112-117.

122.R. Klajn, L. Fang, A. Coskun, M. A. Olson, P. J. Wesson, J. F. Stoddart and B. A. Grzybowski, J Am Chem Soc, 2009, 131, 4233-4235.

30 123.D. Payer, S. Rauschenbach, N. Malinowski, M. Konuma, C. Virojanadara, U. Starke, C. O. Dietrich-Buchecker, J.-P. Collin, J.-P. Sauvage, N. Lin and K. Kern, J Am Chem Soc, 2007, 129, 15662-15667.

124.C. P. Collier, G. Mattersteig, E. W. Wong, Y. Luo, K. Beverly, J.

35 Sampaio, F. M. Raymo, J. F. Stoddart and J. R. Heath, Science, 2000, 289, 1172-1175.

125.J. J. Lee, A. G. White, D. R. Rice and B. D. Smith, Chem Commun, 2013, 49, 3016-3018.

126.H. C. Zhou, J. R. Long and O. M. Yaghi, Chem Rev, 2012, 112, 673-

40 674.

127.Q. W. Li, W. Y. Zhang, O. Š. Miljanić, C. B. Knobler, J. F. Stoddart and O. M. Yaghi, Chem Commun, 2010, 46, 380-382.

128.Q. W. Li, C. H. Sue, S. Basu, A. K. Shveyd, W. Y. Zhang, G. Barin, L. Fang, A. A. Sarjeant, J. F. Stoddart and O. M. Yaghi,

$45 \quad$ Angew Chem Int Edit, 2010, 49, 6751-6755.

129.D. Cao, M. Juríček, Z. J. Brown, A. C. H. Sue, Z. C. Liu, J. Y. Lei, A. K. Blackburn, S. Grunder, A. A. Sarjeant, A. Coskun, C. Wang, O. K. Farha, J. T. Hupp and J. F. Stoddart, Chem-Eur J, 2013, 19, 8457-8465.

50 130.V. N. Vukotic, K. J. Harris, K. L. Zhu, R. W. Schurko and S. J. Loeb, Nat Chem, 2012, 4, 456-460. 